\title{
The role of employment interruptions and part-time work for the rise in wage inequality
}

\author{
Martin Biewen ${ }^{1,2}$, Bernd Fitzenberger $2,3,4,5,6,7^{*}$ (D) and Jakob de Lazzer ${ }^{3}$
}

\author{
*Correspondence: \\ bernd.fitzenberger@wiwi.hu-berlin.de \\ ${ }^{2}$ IZA, Bonn, Germany \\ ${ }^{3}$ Humboldt University Berlin, Berlin, \\ Germany \\ Full list of author information is \\ available at the end of the article
}

\begin{abstract}
The incidence of employment interruptions and temporary part-time work has grown strongly among full-time workers, yet little is known about the impact on wage inequality. This is the first study showing that such episodes play a substantial role for the rise in inequality of full-time wages, considering the case of Germany. While there are also strong composition effects of education for males and of age and experience for females, changes in industry and occupation explain fairly little of the inequality rise. Extending the analysis to total employment reveals substantial negative selection into part-time work.
\end{abstract}

JEL-Classification: J31, J20, J60

Keywords: Wage inequality, Part-time employment, Employment interruptions, Composition effects

\section{Introduction}

The incidence of employment interruptions and temporary part-time work has grown strongly, raising concerns about the stability of employment and low wages among parttime workers (OECD 2010). Less known is that the incidence of previous part-time work and employment interruptions has also grown among full-time workers. However, employment interruptions and part-time experience may be associated with lower future wages due to lower human capital accumulation, negative signalling effects, or lower labor force attachment (Arulampalam 2001; Blundell et al. 2016; Heckman 1981, Paul 2016). The literature on the rise in wage inequality among full-time workers has so far not taken this into account. This is the first study to examine the impact of changes in recent labor market histories on the rise in wage inequality. Re-examining the development of the wage distribution in Germany, we use administrative panel data to investigate the role of composition changes, in particular changes in recent labor market experience, for the rise in wage inequality ${ }^{1}$. As the key novel aspects, our study accounts explicitly for previous part-time work and employment interruptions among full-time employees, and we extend the analysis to total employment.

Motivating our analysis, Fig. 1 shows for the years 1985 and 2010 the number of days in part-time employment and nonemployment, respectively, during the previous 5 years by decile of the wage distribution. For full-timers, both the incidence of previous part-time and nonemployment experience increased considerably between 1985 and 2010. Put differently, full-timers have over time become more likely to have experienced

(c) The Author(s). 2018 Open Access This article is distributed under the terms of the Creative Commons Attribution 4.0 International License (http://creativecommons.org/licenses/by/4.0/), which permits unrestricted use, distribution, and reproduction in any medium, provided you give appropriate credit to the original author(s) and the source, provide a link to the Creative Commons license, and indicate if changes were made. 


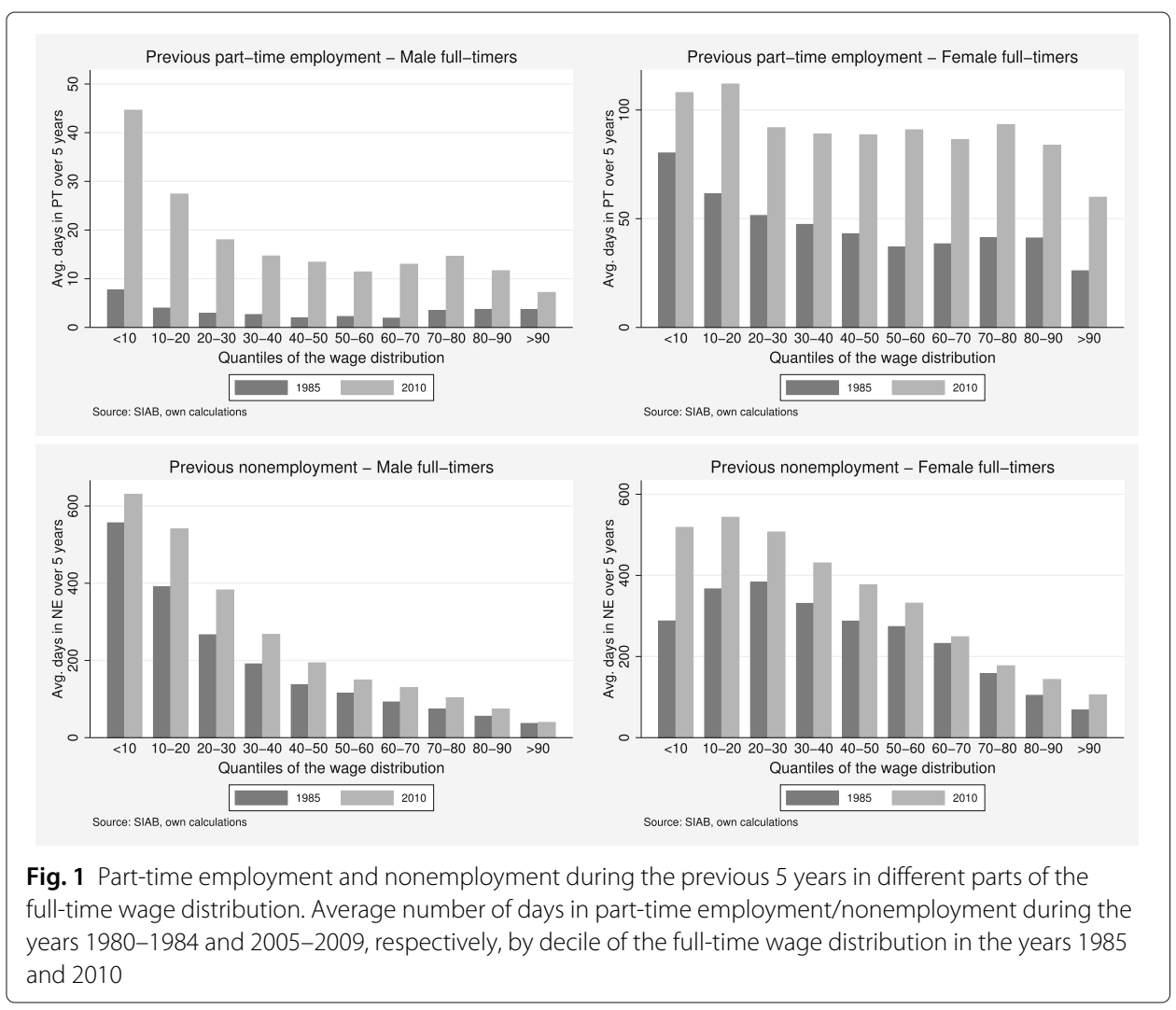

part-time work or employment interruptions in the past. The prevalence of previous parttime experience and nonemployment increases in the lower part of the full-time wage distribution, implying that among workers with particular low wages the share of workers, who have recently worked part-time or who have experienced nonemployment in the recent past, has grown over time. Figure 1 shows that nonemployment experience is more important than part-time experience, with male (female) full-timers in 2010 in the lowest decile having experienced an average of more than 600 (500) days of nonemployment and more than 40 (110) days of part-time employment during the time period 2005 to 2009. The evidence for part-time employment is consistent with studies showing that part-time work has increased strongly and that transitions between part-time and full-time work and employment interruptions have become more frequent (Tisch and Tophoven 2012; Potrafke 2012; Tamm et al. 2017). Below, we will also show evidence that the dispersion of nonemployment and part-time experience among full-timers has grown over time. There was a secular increase of unemployment in Germany from the 1980s until the mid 2000s. Afterwards, unemployment fell almost continuously until 2010 (SVR 2014). Our analysis will focus on long-term changes abstracting form cyclical variation in nonemployment and part-time experience among full-timers ${ }^{2}$.

There is ample evidence suggesting that episodes of part-time work or nonemployment have negative long-term impacts on the career path and therefore on future wages ${ }^{3}$. First, human capital accumulation slows down or there is even depreciation when workers interrupt their career or temporarily downgrade to part-time employment. Second, employment interruptions or part-time experience may lead to scarring effects leading 
to lower wage offers and poorer career possibilities upon re-employment. A third point is that lagged employment outcomes are indicators of permanent characteristics which drive employment and wages. Accordingly, periods of nonemployment or part-time employment in the past may indicate a lower labor force attachment-in addition to being a negative productivity signal. Lagged employment outcomes are unobserved in the crosssectional data sets, typically used in the literature on wage inequality for most countries (see, e.g., Acemoglu and Autor (2011) and the literature discussion in Section 2).

For the aforementioned reasons, our paper investigates the role of employment interruptions and part-time employment in a statistical decomposition of the rise in wage inequality among full-time working employees. In light of the evidence in Fig. 1, the growing importance of part-time employment and nonemployment is likely to play an important role for the increase of lower tail wage inequality. The literature review in Section 2 reveals that the studies on the rise of wage inequality have so far not taken into account the rise in previous nonemployment and part-time employment among fulltimers. Furthermore, little attention has been paid to gender differences in the rise in wage inequality. For instance, negative long-term career effects of transition from full-time to part-time work for women after childbirth have been studied by Connolly and Gregory (2009) and Paul (2016). Fitzenberger et al. (2016) document that women in Germany, who had been working full-time before birth, take fairly long spells of maternity leave after child birth and often then return to part-time work.

Our paper makes the following contributions. First, in our decomposition of the rise in wage inequality among full-timers, we add the previous labor market history involving part-time and nonemployment experience. This plays an important role in explaining the rise in wage inequality both among males and females. At the same time, adding previous labor market history accounts for unobserved heterogeneity in employment decisions. As such, our analysis is of interest for all countries experiencing similar labor market trends, because ours is the first study investigating the role of the rise in nonemployment and part-time employment in explaining the rise in wage inequality among full-time employees. As a related second contribution, we estimate the effect of further observable characteristics to the increase in male and female wage inequality in Germany over the recent decades. Such a parallel analysis for Germany does not exist. Compositional changes in observable characteristics explain over 50 percent of the increase in male wage inequality and up to 80 percent of the increase in female wage inequality. To the best of our knowledge, the extremely strong role of composition effects for the rise of female wage inequality has not been recognized so far. Third, we estimate composition effects with regard to the counterfactual distribution of full-time wages for all employees, which confirms the robustness of our main findings. Furthermore, this shows that part-timers (especially female part-timers) represent a negative selection with respect to observable characteristics. Including part-timers into the analysis also speaks to the role of increasingly heterogeneous labor market histories for the rise in German wage inequality.

The remainder of this paper is structured as follows. Section 2 reviews the literature on the rise of wage inequality. Section 3 discusses the data used and presents first descriptive evidence. Section 4 discusses our findings. Section 5 concludes. The Appendix provides more details and supplementary empirical results. A supplementary appendix with further details is available as Additional file 1. 


\section{Literature review}

Wage inequality has been increasing in many industrialized countries between the 1980s and the 2000s (see the comprehensive survey in Acemoglu and Autor (2011), or the literature discussion in Lemieux (2006), Autor et al. (2008), Dustmann et al. (2009)). Many studies focus on the USA, but the same mechanisms operating in the USA are also at play in other industrialized countries, including Germany. Skill-biased technical change (SBTC) is the most prominent explanation for the rise in wage inequality, predicting rising wage inequality across the entire wage distribution. This is consistent with the evidence for the USA for the 1980s but not for the 1990s, as in the 1990s inequality stopped to grow at the bottom of the wage distribution (Autor et al. 2008). Acemoglu and Autor (2011) take the latter as evidence for the task-based approach (see Autor et al. 2003) implying a falling demand for occupations with medium skill requirements (which are relatively more routine intensive and thus easier to substitute by technology) relative to both occupations with high or with low skill requirements, resulting in polarization of employment across occupations. The evidence regarding a polarization of wages across the wage distribution in the USA seems to be limited to the 1990s, and a polarization of wages is not an unambiguous prediction of the task-based approach (Autor 2013). Some studies for the USA emphasize the role of changing labor market institutions such as de-unionization and falling real minimum wages (see also the discussion in Autor et al. (2003)). DiNardo et al. (1996) show that the fall in unionization levels explains an important part of the rise in wage inequality during the 1980s.

In related work, Lemieux (2006) shows that changes in the composition of the workforce regarding education and experience explain a major part of the rise in wage inequality in the USA. Also, Autor et al. (2008) find strong composition effects, especially for females, but focus on other explanations for the rise in wage inequality. Composition effects also affect residual wage inequality, i.e., the wage differences among employees with the same observable characteristics (DiNardo et al. 1996; Lemieux 2006). Altogether, this evidence motivated us to scrutinize the role of composition effects for the rise of wage inequality in Germany.

Wage inequality has been rising in West Germany [henceforth Germany] since the 1980s (Dustmann et al. 2009) 4 . Until the mid 1990s, the increase in wage dispersion among full-timers was restricted to the top of the wage distribution, whereas wage inequality increased from mid 1990s onwards until 2004 across the entire distribution (Dustmann et al. 2009). The evidence until the mid 1990s is consistent with skill-biased technological change and the hypothesis that labor market institutions such as unions and minimum wages prevented a rise in wage inequality at the bottom of the wage distribution before the mid 1990s, which resulted in rising unemployment among the low-skilled (Fitzenberger 1999). Dustmann et al. (2009) show that changes in the composition of workers regarding age and education and the sizeable decline in coverage by collective bargaining both explain major components of the rise in wage inequality. At the same time, the study provides evidence for a polarization of employment as found previously for the USA (see also Antonczyk et al. 2018).

Antonczyk et al. (2009) and Antonczyk et al. (2010) find a strong increase of wage inequality between 1999/2001 and 2006. Changes in task assignments cannot explain this rise (Antonczyk et al. 2009). Accounting for coverage by collective bargaining, firmlevel characteristics, and personal characteristics, Antonczyk et al. (2010) show that the 
decline in coverage by collective bargaining does not explain the rise in wage inequality in the lower part of the wage distribution, when firm-level characteristics are held constant. Most important are changes in the quantile regression coefficients of firm-level variables (firm size, region, industry), which reflect a growing heterogeneity in firm-level wage policies. The two studies differ regarding the contribution of changes in personal characteristics. Biewen and Seckler (2017) find that changes in union coverage and personal characteristics are most important for the rise in wage inequality between 1995 and 2010. Card et al. (2013) estimate person and firm fixed effects in wages. The study finds a growing heterogeneity of these fixed effects over time and increasing sorting of workers with high personal fixed effects into firms with high firm fixed effects. Both effects contribute strongly to the rise in wage inequality. Felbermayr et al. (2014) find that the decline in coverage by collective bargaining is the most important explanation for the rise in wage inequality, while there is no important role for international trade. Our short survey of the literature shows that the literature has not yet reached a consensus on the mechanisms behind the rise in wage inequality in Germany until $2010^{5}$.

None of the aforementioned studies investigates to what extent the rise in interruptions of full-time work is driving the increase in wage inequality, although there is ample evidence of a negative effect of previous nonemployment and part-time experience on wages in full-time employment. Several mechanism may be at work. First, human capital accumulation slows down or there is even depreciation when workers stop working full-time (Beblo and Wolf 2002; Manning and Petrongolo 2008; Edin and Gustavsson 2008; Paul 2016). Employment interruptions due to displacement have been shown to negatively affect wages (Burda and Mertens 2001, Schmieder et al. 2010, Edler et al. 2015). After maternity leave, females often return to part-time employment, but may return to full-time work later on (Fitzenberger et al. 2016; Paul 2016). When a transition from nonemployment or part-time work back into full-time work involves a job change (no recall), this also implies a loss of job-specific human capital. Second, employment interruptions or part-time experience may lead to scarring effects, i.e., employers (rightly or wrongly) interpret previous non-full-time employment as signal of low productivity or low labor force attachment leading to lower wage offers and poorer career possibilities upon re-employment (Ruhm 1991; Arulampalam 2001; Gregory and Jukes 2001). A third potential mechanism, similar to the second, is that lagged employment outcomes are indicators of permanent characteristics which drive employment and wages (Heckman 1981). Accordingly, periods of nonemployment or part-time employment in the past may indicate a lower labor force attachment-in addition to being a negative productivity signal.

The literature on wage effects of temporary part-time work focuses primarily on women and maternal part-time. For females in the UK, Connolly and Gregory (2009) and Blundell et al. (2016) demonstrate that part-time employment in the past results in lower earnings trajectories, even when returning to full-time work. Connolly and Gregory (2009) also show that this holds for part-time episodes at the same employer. They point out that part-time work is often related to downgrading to less skilled tasks that persists if the individual later returns to full-time work. Controlling for selection on unobservables, Paul (2016) finds for Germany a substantial negative impact of part-time work and nonemployment episodes on future earnings of females in full-time work, with the effect being even stronger for nonemployment. While there is no detailed analysis of part-time effects 
among males available, the mechanisms of human capital depreciation and lack of further training which underly the wage effects of part-time work for female workers are likely to affect male workers in a similar way.

\section{Data and descriptive evidence}

Our analysis uses SIAB data involving a $2 \%$ sample of all dependent employees who are subject to social security contributions, i.e., excluding the self-employed and civil servants ${ }^{6}$. We study the period 1985 to 2010 . Even though SIAB data are available for earlier years, we do not include them in our analysis because the rise of wage inequality across the entire distribution is only observed after the 1980s (Dustmann et al. 2009; Fitzenberger 2012). Since we may observe several employment spells of various lengths per individual in a given year, all observations are weighted with the share of days worked in a job in the respective year. The sampling weights calculated in this way reflect the relative importance of each wage observation.

We account for an individual's labor market history using four measures. The first two involve the number of days spent in full-time and in part-time employment during the last 5 years. The residual category is the number of days spent in nonemployment during the last 5 years, which may be times of unemployment, education, or any other type of nonemployment. In addition, we use two dummy variables, indicating whether a person had a full-time or a part-time spell at any point during the previous year. This information captures individual short-term employment dynamics. Wages are daily wages in Euros deflated by the CPI to 1990. Since we use administrative data on employment spells, the measures are very precise. Because the SIAB data do not involve hours worked, we follow the literature on wage inequality for Germany and use daily wages, representing an earnings measure. Our sample also includes individuals with part-time employment, but the wage data for part-timers are much more confounded by differences in hours of work than for full-timers ${ }^{7}$. Below, we also estimate the counterfactual distribution of full-time wages for total employment also including part-timers.

All wages above the contribution threshold are top-coded in the SIAB. The censoring threshold lies above the $85 \%$ wage quantile in every year. Therefore, we compare the $85 / 15$, the $85 / 50$, and the $50 / 15$ quantile gaps in the wage distribution. In those cases, where we cannot restrict our analysis to values below the $85 \%$ quantile (in particular when analyzing developments in wage residuals), we impute wages above the threshold according to individual characteristics. Details of the imputation procedure can be found in the Appendix, "Imputation of wages above censoring threshold" section. Unless noted otherwise, we restrict our analysis to individuals aged 20 to 60 years, in order to focus on the working age population.

Table 1 lists the covariates used and Table 2 provides descriptive statistics for two sample years. We distinguish three education levels: University degree (including Universities of Applied Sciences), degree from Upper secondary school and/or Vocational Training, No/Other degree. We use 14 aggregated industries (German Industry Classification [WZ] 1993) and 63 aggregated occupations (2-digit level of the KldB ["Klassifikation der Berufe"] 1988). For interactions between industry and occupation, we aggregate occupations to the 1-digit level in order to avoid problems with empty cells in our logit regressions. The education variable is cleaned, and interrupted measurements are imputed for consistency based on Fitzenberger et al. (2006). 
Table 1 Variable classification

\begin{tabular}{|c|c|c|}
\hline Variable group & Short & Variable list \\
\hline Education & Ed & $\begin{array}{l}3 \text { categories (ed): University, Upper secondary High-School } \\
\text { and/or Vocational Training, No/Other Degree }\end{array}$ \\
\hline Experience & Ex & Potential experience (age-years of schooling-6) (ex) \\
\hline Labor market history & Hist & $\begin{array}{l}\text { Number of days in full-time }(f t 5) \text {, or part-time }(p t 5) \text { over the } \\
\text { last } 5 \text { years. Indicators for: full-time job in previous year }(f t) \\
\text { part-time job in previous year }(p t)\end{array}$ \\
\hline Occupation & Occ & Job classification by KldB 2-digit levels (occ, 63 categories) \\
\hline Industry & Ind & Industry classification by WZ93 (sec, 14 categories) \\
\hline
\end{tabular}

\subsection{Wage inequality}

Figure 2 shows the development of log wage quantiles (cumulative changes) from 1985 onwards. Our primary measures of wage inequality are the gaps between the 85th, 50th, and 15th percentiles of $\log$ wages. Until about 1991, the different wage quantiles move upward and largely in parallel. After 1991, median wages of male full-timers stagnate (recall that we analyze real wages). For female full-timers there is a continuous but decelerating rise until 2003 and a subsequent decline until 2008. For both genders, we observe a widening of the wage distribution beginning just at the time when median wages start stagnating. Wages at the 85 th percentile continue to increase, while wages at the 15 th percentile decline. For males, this decline is moderate until the early 2000s but accelerates afterwards. By 2010, male wages at the 15th percentile even lie below their 1985 level. For females, we observe different developments of the three quantiles already in the late 1980s. However, inequality only increases in a more substantial way in the late 1990s, several years later than for males. After 1998 female median wages stagnate, while the 85th percentile rises and the 15 th percentile declines rapidly. The corresponding trends in inequality as measured by the $85 / 50$ and 50/15 gaps are depicted by the solid lines in Figs. 10, 11, 12, and 13 .

\subsection{Labor market histories}

Part-time work in Germany has grown substantially over the last decades (Fig. 3). While this may reflect secular trends in labor market participation, part of the increase is linked to political reforms promoting part-time work. Over our observation period, several changes in legislation focus on part-time work. In 1985, the German government enacted a law (Beschäftigungsförderungsgesetz) which granted part-timers the same level of job protection as full-timers. This law increased the acceptance of part-time work on the side of trade unions and in the general population. In 2001, a law followed which made it easier for employees to enter voluntary part-time work (Teilzeit-und Befristungsgesetz). These changes in legislation had the effect of formally easing the transition between full-time, part-time, and nonemployment. We observe that not only the yearly stock of part-time employees increased for both genders, but that the frequency of temporary part-time episodes for individuals currently working full-time increased as well (Fig. 4). Parallel to the rise of part-time work, two changes in legislation between 1985 and 1998 (Beschäftigungsförderungsgesetz, Arbeitsförderungs-Reformgesetz) facilitated fixed-term contracts and temporary agency work.

Both the intensive and the extensive margin of labor market histories matter for current wages (Burda and Mertens 2001; Arulampalam 2001; Beblo and Wolf 2002; Manning and 
Table 2 Descriptives of full-time samples

\begin{tabular}{|c|c|c|c|c|}
\hline & \multicolumn{2}{|l|}{1985} & \multicolumn{2}{|l|}{2010} \\
\hline & Mean & sd & Mean & sd \\
\hline \multicolumn{5}{|l|}{ Male full-time sample } \\
\hline Real wage in Euro & 70.06 & 47.53 & 82.48 & 48.34 \\
\hline Log real wage & 4.16 & 0.39 & 4.28 & 0.51 \\
\hline No/other degree indicator & 0.19 & 0.40 & 0.08 & 0.28 \\
\hline Vocational degree indicator & 0.71 & 0.46 & 0.71 & 0.45 \\
\hline University degree indicator & 0.07 & 0.25 & 0.15 & 0.36 \\
\hline Work experience & 27.34 & 11.19 & 28.98 & 10.13 \\
\hline No. of days in full time last 5 years & 1546.04 & 487.51 & 1523.88 & 513.84 \\
\hline Fulltime spell in previous year? & 0.96 & 0.19 & 0.96 & 0.20 \\
\hline No. of days in part time last 5 years & 3.26 & 46.49 & 15.72 & 113.47 \\
\hline Part-time spell in previous year? & 0.00 & 0.05 & 0.01 & 0.09 \\
\hline Agriculture and mining & 0.03 & 0.17 & 0.02 & 0.13 \\
\hline Plastics, rubber, mineral products & 0.03 & 0.17 & 0.03 & 0.17 \\
\hline Chemicals & 0.03 & 0.18 & 0.02 & 0.15 \\
\hline Machinery and metal products & 0.15 & 0.36 & 0.13 & 0.33 \\
\hline Transport- and electrical equipment & 0.12 & 0.32 & 0.11 & 0.31 \\
\hline Food and basic consumption & 0.10 & 0.31 & 0.07 & 0.25 \\
\hline Hotels and restaurants & 0.01 & 0.11 & 0.02 & 0.13 \\
\hline Construction & 0.12 & 0.32 & 0.08 & 0.28 \\
\hline Trade & 0.12 & 0.33 & 0.14 & 0.35 \\
\hline Transport and communication & 0.06 & 0.24 & 0.07 & 0.26 \\
\hline Financial and insurance & 0.08 & 0.27 & 0.18 & 0.38 \\
\hline Public services & 0.04 & 0.20 & 0.05 & 0.21 \\
\hline Health and Education & 0.03 & 0.18 & 0.05 & 0.23 \\
\hline Public administration & 0.06 & 0.24 & 0.04 & 0.20 \\
\hline \multicolumn{5}{|l|}{ Female full-time sample } \\
\hline Real wage in Euro & 46.24 & 20.34 & 61.02 & 35.16 \\
\hline Log real wage & 3.74 & 0.44 & 3.97 & 0.56 \\
\hline No/other degree indicator & 0.27 & 0.45 & 0.08 & 0.27 \\
\hline Vocational degree indicator & 0.66 & 0.47 & 0.73 & 0.44 \\
\hline University degree indicator & 0.03 & 0.16 & 0.12 & 0.32 \\
\hline Work experience & 24.03 & 11.90 & 27.39 & 11.14 \\
\hline No. of days in full time last 5 years & 1356.01 & 598.16 & 1327.35 & 625.94 \\
\hline Fulltime spell in previous year? & 0.93 & 0.26 & 0.93 & 0.26 \\
\hline No. of days in part time last 5 years & 45.97 & 210.01 & 88.99 & 292.80 \\
\hline Part-time spell in previous year? & 0.02 & 0.15 & 0.04 & 0.20 \\
\hline Agriculture and mining & 0.01 & 0.08 & 0.01 & 0.08 \\
\hline Plastics, rubber, mineral products & 0.02 & 0.14 & 0.01 & 0.11 \\
\hline Chemicals & 0.02 & 0.15 & 0.02 & 0.13 \\
\hline Machinery and metal products & 0.05 & 0.23 & 0.04 & 0.19 \\
\hline Transport- and electrical equipment & 0.08 & 0.27 & 0.05 & 0.21 \\
\hline Food and basic consumption & 0.13 & 0.34 & 0.06 & 0.25 \\
\hline Hotels and restaurants & 0.03 & 0.18 & 0.03 & 0.18 \\
\hline Construction & 0.02 & 0.14 & 0.02 & 0.13 \\
\hline Trade & 0.18 & 0.38 & 0.16 & 0.36 \\
\hline Transport and communication & 0.02 & 0.16 & 0.04 & 0.19 \\
\hline Financial and insurance & 0.12 & 0.33 & 0.21 & 0.40 \\
\hline Public services & 0.06 & 0.23 & 0.06 & 0.24 \\
\hline Health and Education & 0.17 & 0.38 & 0.24 & 0.42 \\
\hline Public administration & 0.08 & 0.27 & 0.06 & 0.24 \\
\hline
\end{tabular}




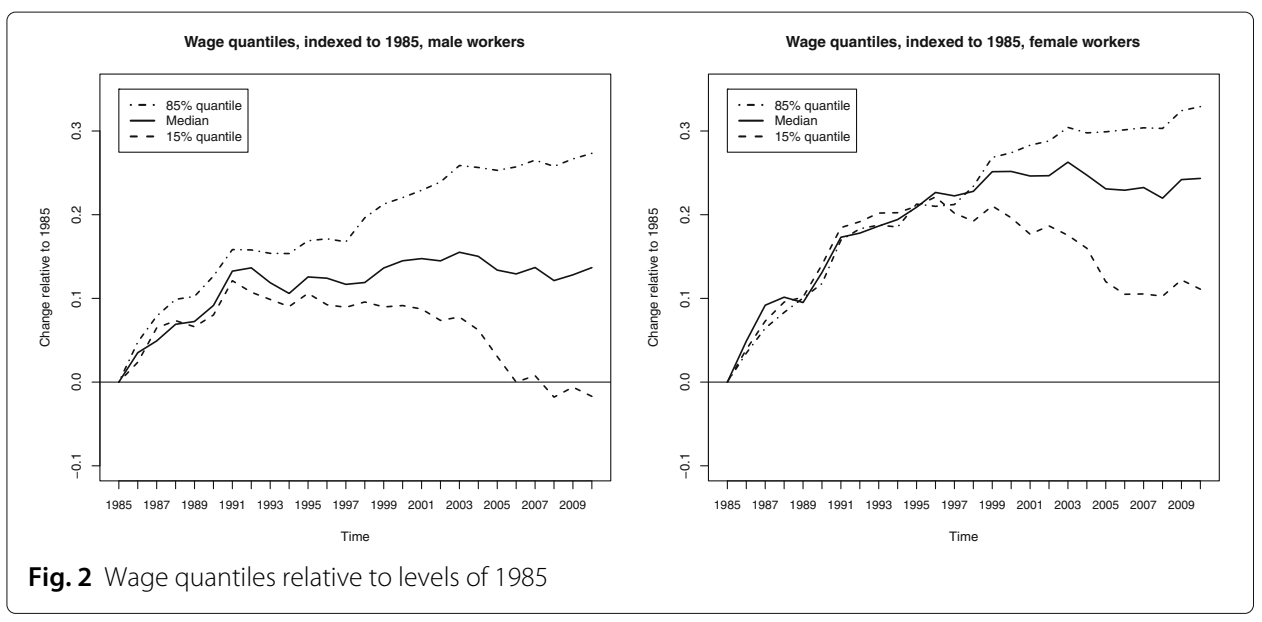

Petrongolo 2008; Edin and Gustavsson 2008; Schmieder et al. 2010; Edler et al. 2015; Paul 2016; Blundell et al. 2016). Returns to labor market experience are not uniform across jobs and type of work. Not only is experience in part-time work valued lower than that in fulltime work, but part-time and nonemployment episodes slow down career progression and wage growth (see literature review in Section 2).

Figure 4 shows increasing average lengths and also increasing variability of previous part-time episodes for men and females, both above and below the median of the respective wage distribution ${ }^{8}$. The mean and variance of number of days spent in part-time work during the last 5 years increases over time for those individuals who are in full-time jobs at the time of observation. Male full-timers experience a noticeable increase in the past part-time episodes, although the total amount of the time previously spent in part-time is lower than for females. While the increase in prevalence of previous part-time for males is only slightly higher below than above the median, the increase in variability of previous part-time experience is considerably stronger below the median. This means that previous part-time episodes are increasingly concentrated on low-wage full-timers which may

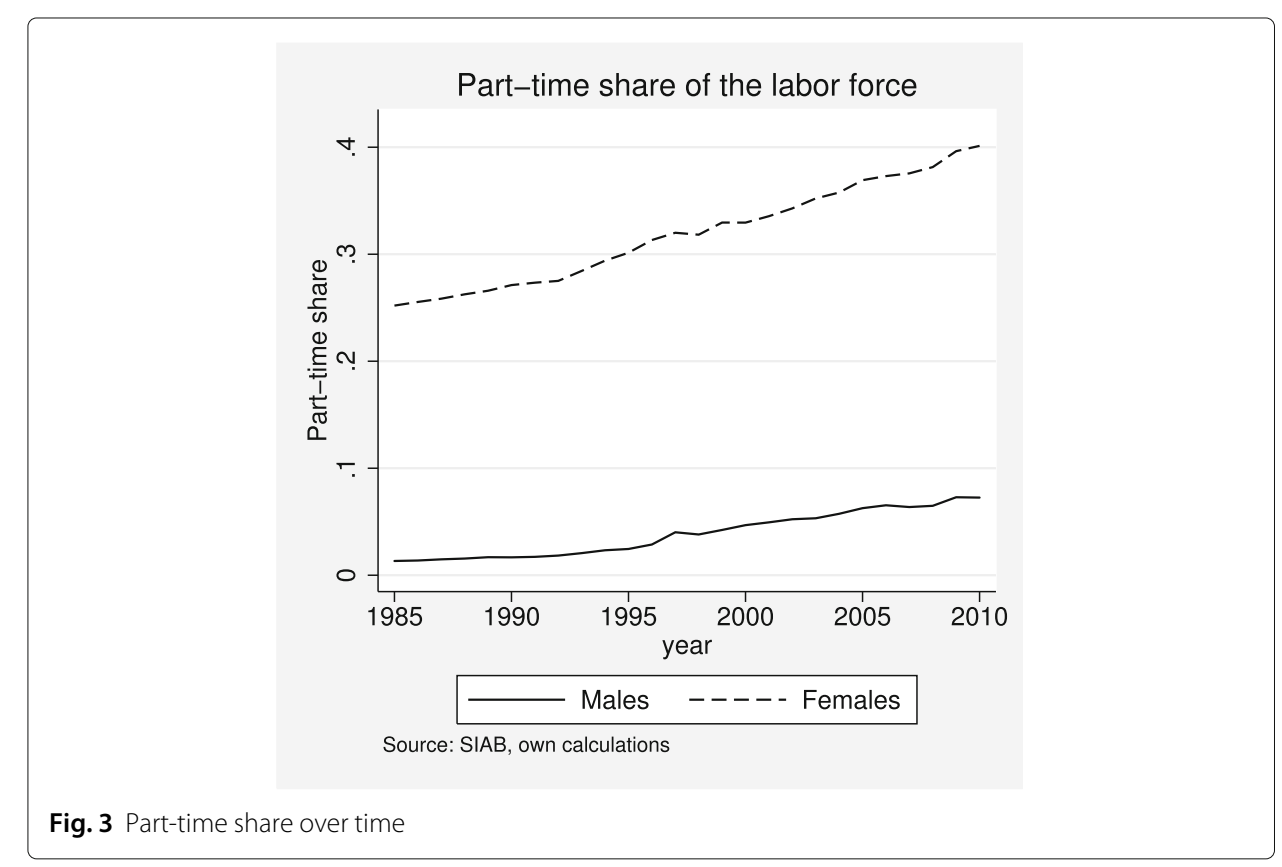




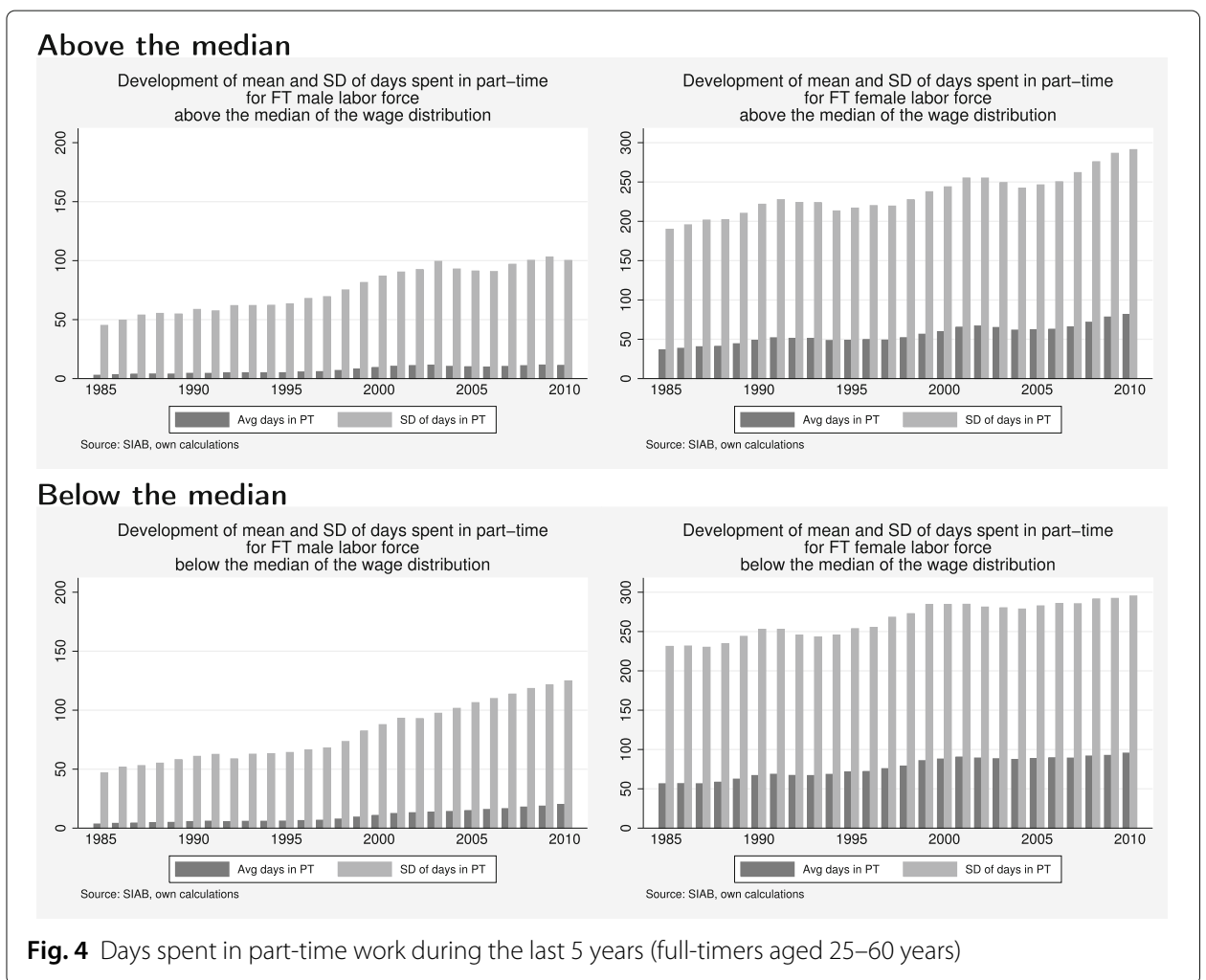

lead to rising lower-tail wage inequality ${ }^{9}$. For female full-timers, we observe an increase in the length and variability of previous part-time work both above and below the median, and the overall levels are considerably higher than for males. Incidentally, the part-time experience of full-time females above the median of the distribution shows stronger cyclical variation compared to females below the median, whose part-time experience follows more of a secular upward trend. Note that the labor supply of females is known to be more elastic than that of men and that the part-time experience of females is often related to career interruptions after child birth (Blundell et al. 2016).

There are two further issues concerning temporary part-time episodes to be discussed $^{10}$. The first involves working time accounts which provided a buffer against the negative labor demand shock in Germany during the Great recession 2008/2009 (Burda and Hunt 2011). The SIAB data do not record a variation in hours worked over a year in case of continuous employment at the same employer. In the case of working time accounts, the part-time/full-time classification is based upon agreed (contractual) hours of work. Furthermore, the data involve daily wages defined as total earnings over an employment spell (typically 1 year, when the worker is employed by the same employer for one calendar year) divided by the length of the employment spell in days. Specifically, working time accounts allow to vary the actual hours of work over a year, but there is no variation in monthly earnings. Furthermore, on average over the employment spell the actual hours of work should correspond to the contractual ones. Note further that working time accounts did not play an important role before 2008 and that they show a strong cyclical variation. By contrast, our results below suggest an earlier timing of the distributional effects of previous part-time episodes, reflecting a long-term continuous trends which dominates the cyclical variation. The second issue concerns whether the 
part-time episodes in our data are with the same employer or with different employers. A recent study shows that a major part of the cyclical variation in part-time employment in the UK and the USA is accounted for by changes in transitions rates between parttime and full-time work at the same employer (Borowczyk-Martins and Lalé 2018). We would expect wage penalties associated with previous part-time episodes to be larger if they occur across employers. Our data show that the vast majority (about 75-80\%) of transitions from part-time to full-time employment involve a change of employers (see Fig. 5). We observe only a minor cyclical variation in the division of the part-time to fulltime transitions within and between employers, which is unlikely to be of importance in explaining the continuous long-term rise in wage inequality (see decomposition results in Section 4).

We now turn to the descriptive discussion of previous nonemployment episodes. Just as previous part-time experience, nonemployment has a sizeable negative impact on wages. Nonemployment may include all alternative activities such as education or child care or it may be due to involuntary displacement, unemployment, or voluntary absence from the labor market. Such events may lead to human capital obsolescence, with the possible exception of educational spells, and therefore to a decline in wages (Burda and Mertens 2001, Schmieder et al. 2010, Edler et al. 2015). Figure 6 shows the average length and variability of time spent in nonemployment over the past 5 years. Both above and below the median, males and females exhibit increasing previous nonemployment experience. Cross-sectional variability only increases below the median, and there is a cyclical variation, which is stronger below the median. To investigate whether educational spells are driving our results, we reduce the sample to individuals age 30 years or above, for whom we assume that educational spells play a negligible role among nonemployment episodes (see Fig. 17 in the Appendix). Above the median wage, the upward trend now disappears. By contrast, males and females below the median wage still exhibit increasing previous nonemployment experience together with increasing cross-sectional variability. Thus, previous nonemployment episodes are increasingly concentrated on individuals in the lower part of the wage distribution, a trend which may have a strong impact on lower-tail wage inequality. The differences between Figs. 6 and 17 reveals that educational spells are an important part of previous nonemployment episodes among younger workers ${ }^{11}$.

Irrespective of the type of previous nonemployment episodes, their incidence is higher than previous part-time employment, especially for males but also for females. Moreover, the associated wage losses are likely to be larger than those from part-time episodes

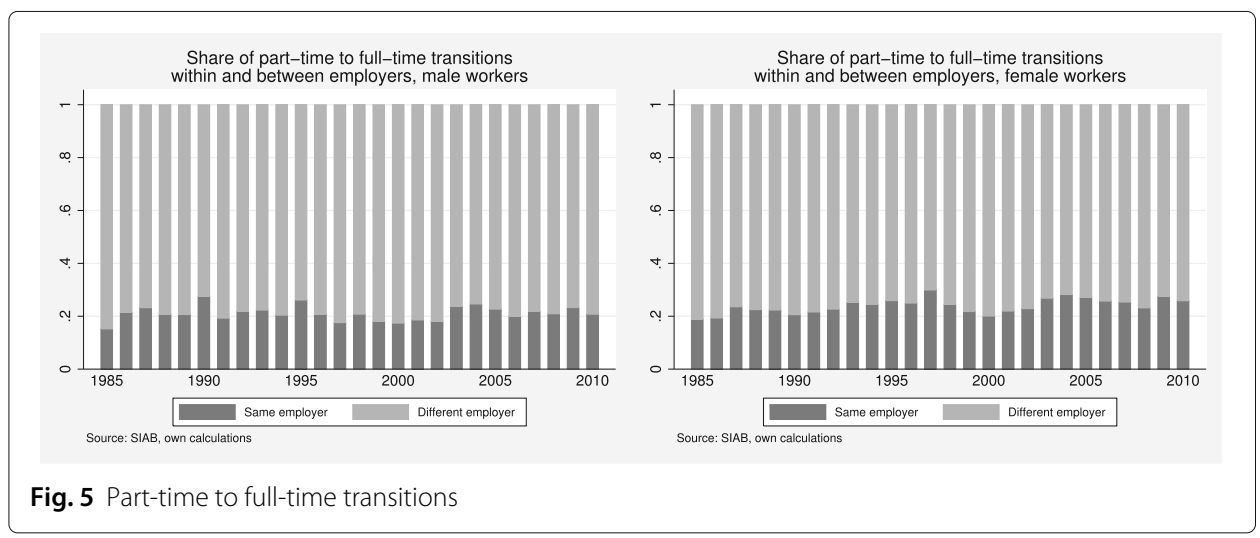




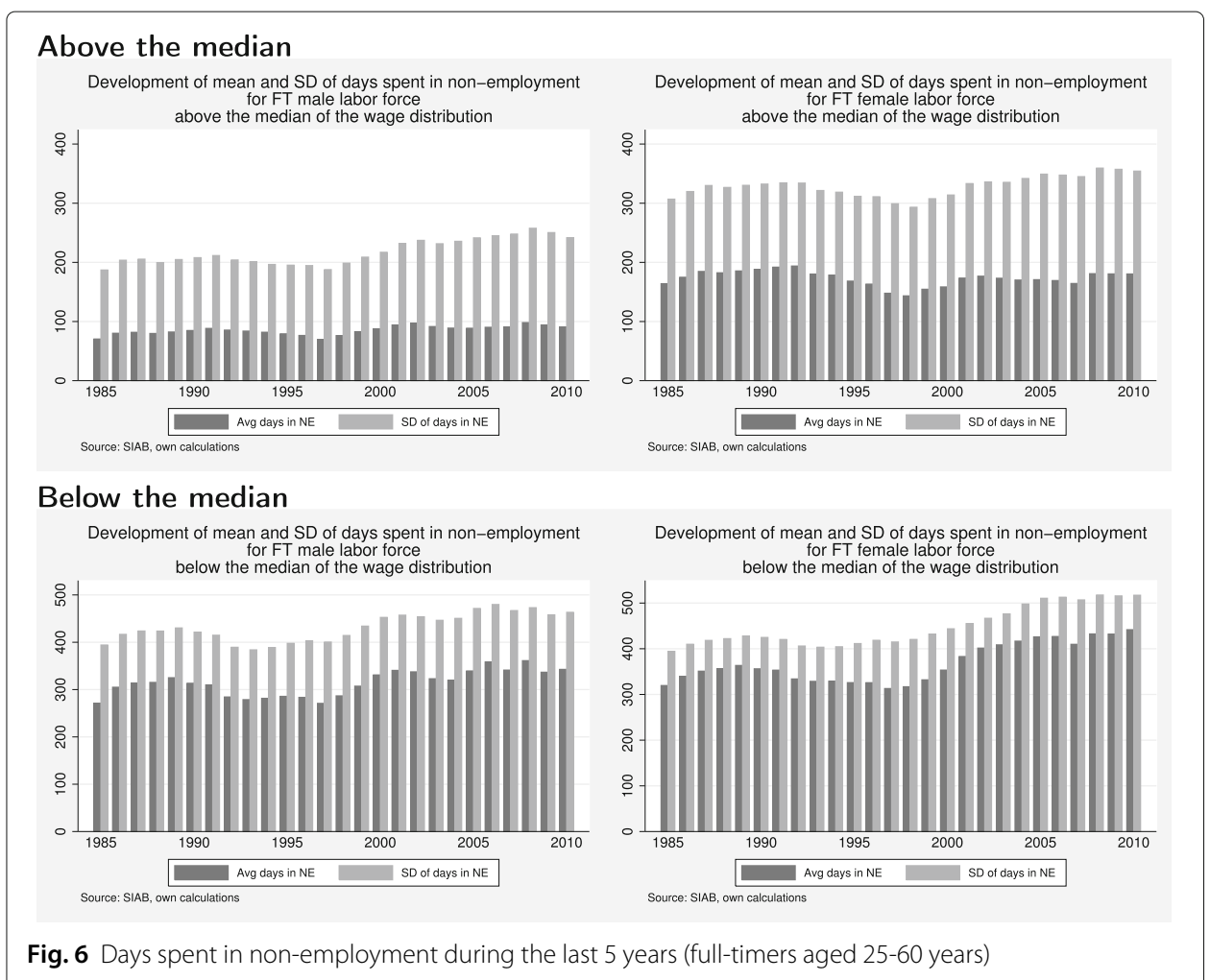

(except for educational spells among younger workers, which may, however, be captured in our subsequent analysis by a higher education level). We therefore expect previous nonemployment episodes to have sizeable negative effects on wages, most likely raising lower-tail wage inequality.

\subsection{Education, experience, industry, and occupation}

In addition to the changes in recent labor market history, there have been strong changes in the distribution of education, work experience, and industry structure. Figure 7 shows the percentage of workers in each education category. The share of workers without an educational degree has declined since the 1980s. This holds in particular for female workers, among whom the percentage of unskilled workers decreases from $32 \%$ in 1985 to $18 \%$ in 2010 . We also observe an increase in the share of university graduates. Again, this is most pronounced for females, as the initial percentage of female university graduates is very small in 1985 but catches up to the male share by 2010. For the medium-skilled, i.e., workers with an upper secondary degree or a vocational degree, we observe a humpshaped development. The share of medium-skilled increases during the late 1980s and the 1990s reaches its peak in the late 1990s and declines in the 2000s, giving way to a rising share of university graduates.

The corresponding trends for the distribution of worker's potential experience are shown in Fig. 8. Between 1985 and 2010, the percentage of highly experienced workers with 27 or more years of potential experience increases, reflecting the aging of the population. The share of workers with medium levels of potential experience (between 14 and 26 years) follows a hump-shaped trend. The percentage of older workers with 40 or more years of experience did not undergo major changes in our sample, even though the overall 


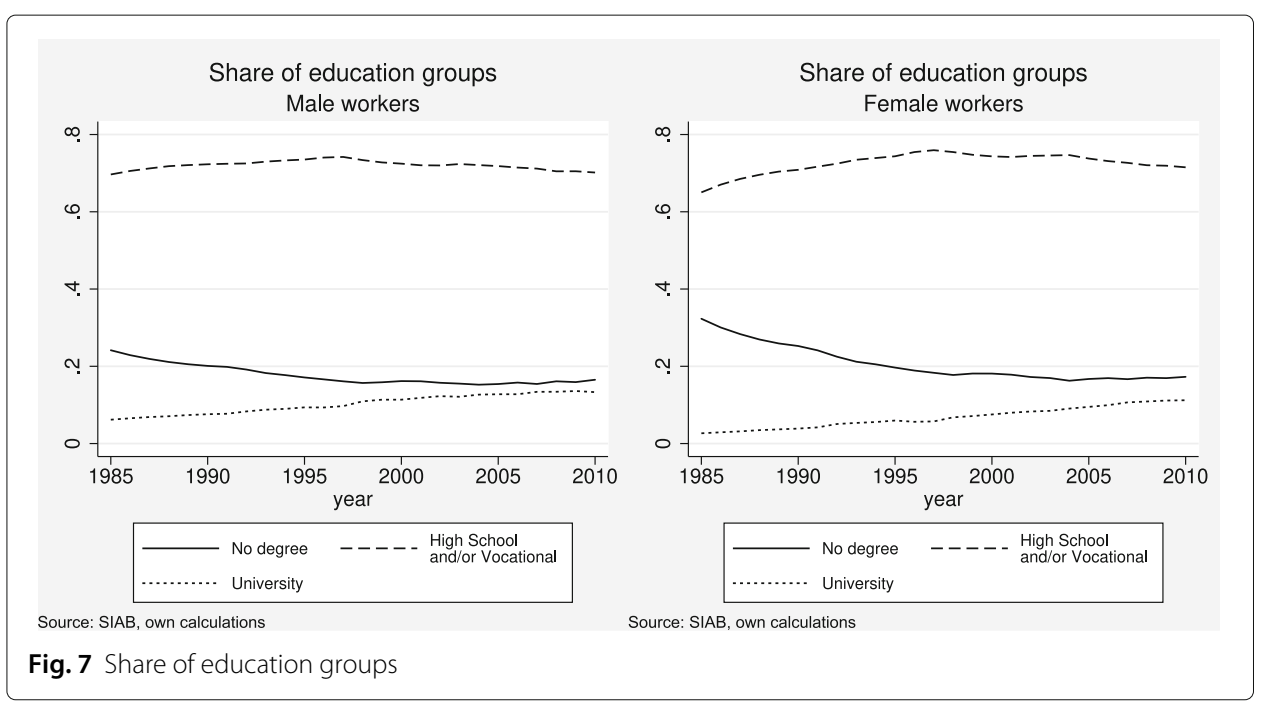

population aged considerably. The only major gender difference in potential work experience concerns the share of workers with low experience. Among males, this share is never higher than $20 \%$ and it drops to $10 \%$ in the late 1990 s. Starting at $30 \%$ in 1985 , the initial share of young female workers is very high but converges to the low level for males in the late 1990s. After the catching-up process among females, the experience composition by gender has become very similar by 2010 . Note that our experience measure is potential work experience which mainly reflects both workers' age and educational periods. In this way, we more clearly separate long-term trends in experience (population aging and educational periods) from the factors we intend to capture in our recent labor market histories (recent part-time and nonemployment episodes).

Figure 9 shows the development of industry shares for eight aggregated sectors. We observe some sectors with an almost constant share since the 1980s (i.e., transportation and trade), while others experiences strong changes. For males, the largest changes are observed for the construction industry, the manufacturing sector for consumer goods, and the banking and insurance sector. The first two experience a massive decline, while

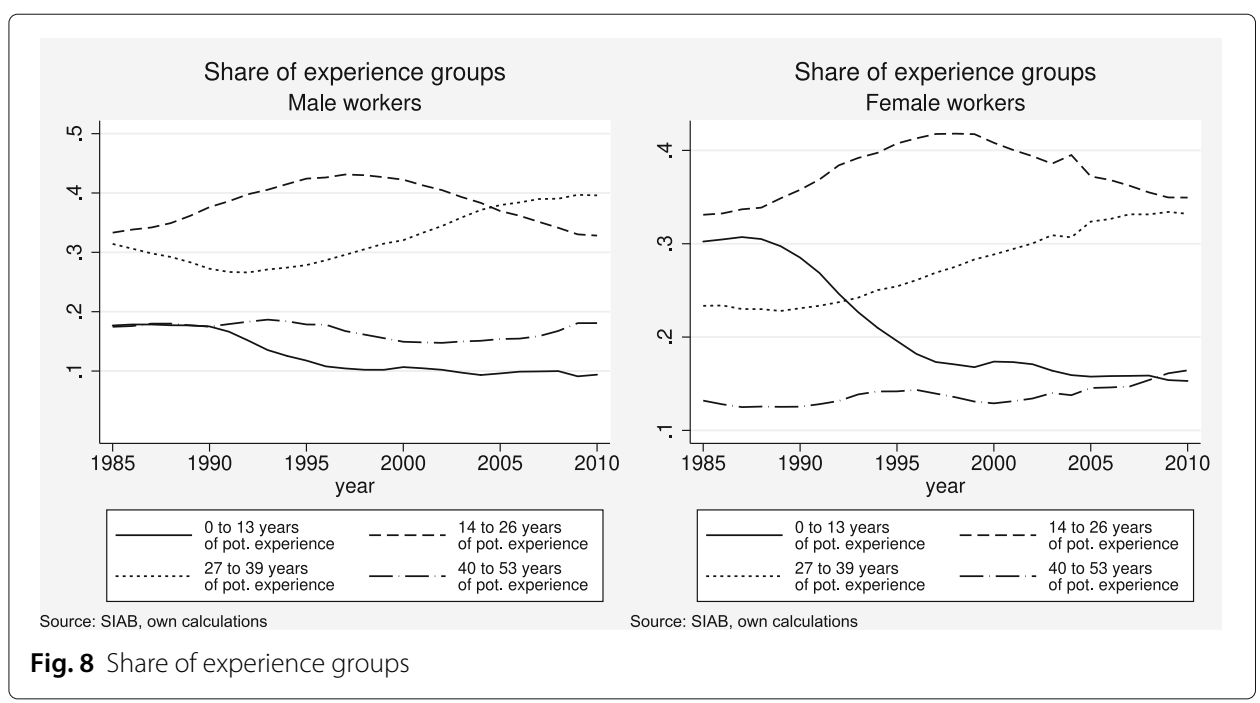




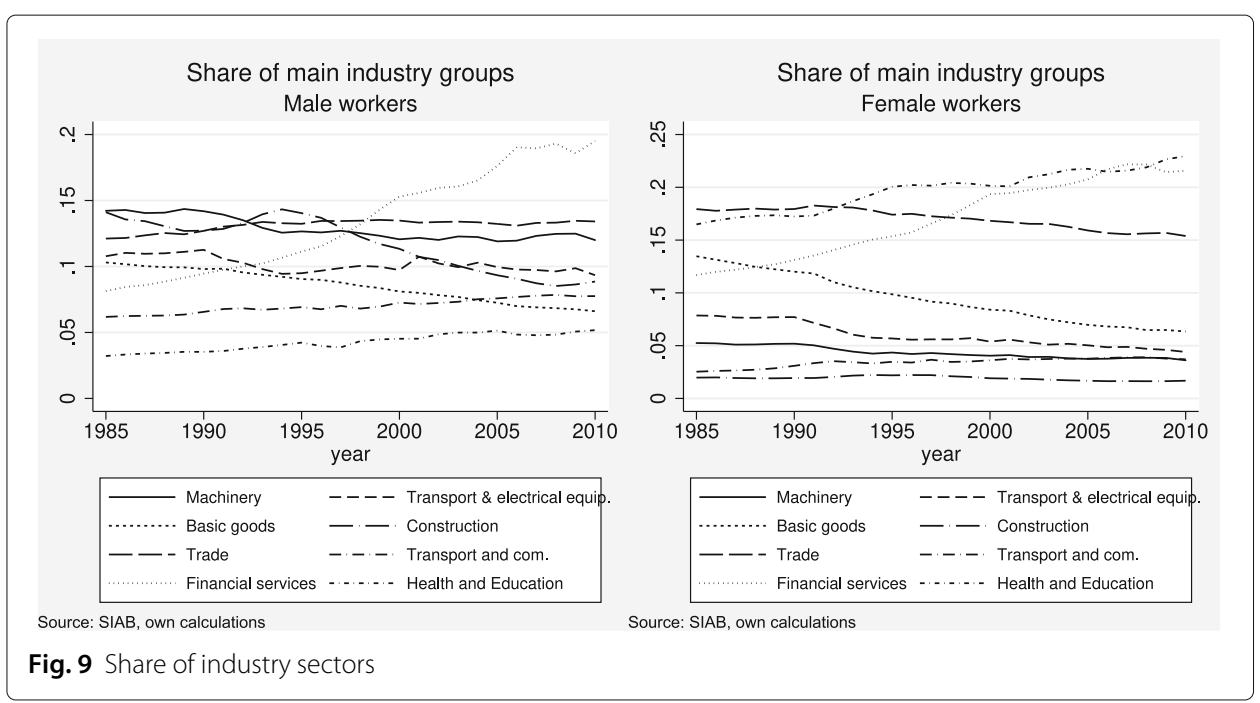

the latter more than doubles its share between 1985 and 2010. Transport and communication as well as health and social services show small increases, whereas the manufacturing sectors for vehicles and for machinery shrink slightly. The initial sector composition differs strongly by gender, but the dynamics of the different sectors are quite similar. In particular, manufacturing declines strongly, while banking and health services grows. The construction sector, which plays no important role for females, does not change in any substantial way.

Shifts between occupations are smaller than those between industries. Table 3 reports the five most frequent occupations in 1985 and 2010. Figure SA2 in the Additional file 1 shows a continuous shift in the aggregate from manufacturing to service sector occupations. At the same time, there are fairly small changes in the distribution of the 63 two-digit occupations. Among males, four out of five occupations are present in the top 5 in both years and their shares are similar. For females, three out of five occupations remain in the top 5 in both years. Furthermore, the correlation coefficient between employment

Table 3 Most frequent occupations 1985 and 2010 (top 5)

\begin{tabular}{|c|c|c|c|c|}
\hline & \multicolumn{2}{|l|}{1985} & \multicolumn{2}{|l|}{2010} \\
\hline & Occupation & Share (\%) & Occupation & Share \\
\hline \multicolumn{5}{|c|}{ Male workers } \\
\hline Rank 1 & Transportation & 5.8 & Office workers & 7.9 \\
\hline Rank 2 & Metalworkers & 5.6 & Transportation & 6 \\
\hline Rank 3 & Office workers & 5.5 & Storage workers & 5.1 \\
\hline Rank 4 & Technicians & 5.0 & Retail workers & 5.1 \\
\hline Rank 5 & Storage workers & 4.8 & Technicians & 5.0 \\
\hline \multicolumn{5}{|c|}{ Female workers } \\
\hline Rank 1 & Office workers & 25.5 & Office workers & 26.9 \\
\hline Rank 2 & Retail workers & 11.3 & Healthcare & 12.4 \\
\hline Rank 3 & Healthcare & 9.2 & Retail workers & 9.8 \\
\hline Rank 4 & Assembly workers & 4.1 & Social workers & 6.9 \\
\hline Rank 5 & Cleaning & 3.7 & Banking \& Insurance & 3.5 \\
\hline
\end{tabular}


shares for the 63 two-digit occupations in 1985 and 2010 is .91 for males and .96 for females.

\section{Empirical analysis}

\subsection{Estimation of counterfactuals}

First, we analyze the impact of composition changes on wage inequality among full-timers accounting for the selection into full-time work based on observed worker characteristics. For the counterfactual analysis keeping characteristics constant over time, we use the reweighting methodology introduced by DiNardo et al. (1996) ${ }^{12}$. Then, we repeat the analysis for wage inequality for total employment in a similar way. We now provide a brief overview of what we do (full formal details can be found in the Appendix).

We start to estimate the distribution of full-time wages which would result if the distribution of worker characteristics had not changed over time while the conditional wage distribution given worker characteristics changed over time as observed ${ }^{13}$. For example, we hold fixed the composition with respect to education and estimate as counterfactual by how much inequality would have risen if workers' education had not changed. We sequentially add groups of covariates in order to determine the incremental effect of a particular set of covariates. For example, in the situation in which we already leave education constant, we also fix workers' potential work experience in order to determine the incremental effect of experience to rising wage inequality. Our sequential conditioning scheme is such that we move from exogenous and predetermined characteristics towards characteristics that are the likely consequence of endogenous decisions of the individual. Altogether, we start with workers' education and sequentially add the factors potential work experience, recent labor market history as well as workers' occupation and industry (see Table 1). As in Lemieux (2006), we also carry out our decomposition for residual wage inequality, i.e., wage inequality within groups of workers with identical observed characteristics.

In the second part of our analysis, we take the distribution of full-time wage earners, but reweight their characteristics to replicate the distribution of observed characteristics for total employment, i.e., including part-time workers. This estimates the counterfactual wage distribution that would result if all employed workers worked full-time. Contrasting this distribution with the wage distribution among full-timers allows one to gauge to which extent part-timers represent a positive or negative selection compared to fulltimers. We repeat our sequential analysis of adding different groups of covariates for the reweighted sample representing total employment.

\subsection{Wage inequality among full-timers}

Starting with male full-timers, we first analyze the effect of educational upgrading on male wage inequality. Figure 10 (left panel) shows the evolution of the quantile gaps in male wages between 1985 and 2010 under the assumption that the 1985 distribution of education is held fixed over time. It turns out that fixing education considerably reduces the increase in inequality, i.e., the observed educational upgrading contributes strongly to the observed rise in wage inequality. Table 4 shows that a share of $17.1 \%$ of the increase in overall inequality (as measured by the $85 / 15$ quantile ratio) and $37.5 \%$ of the increase in the upper half of the distribution (as measured by the 50/15 quantile ratio) can be explained by changes in education, while these changes did not contribute to rising 


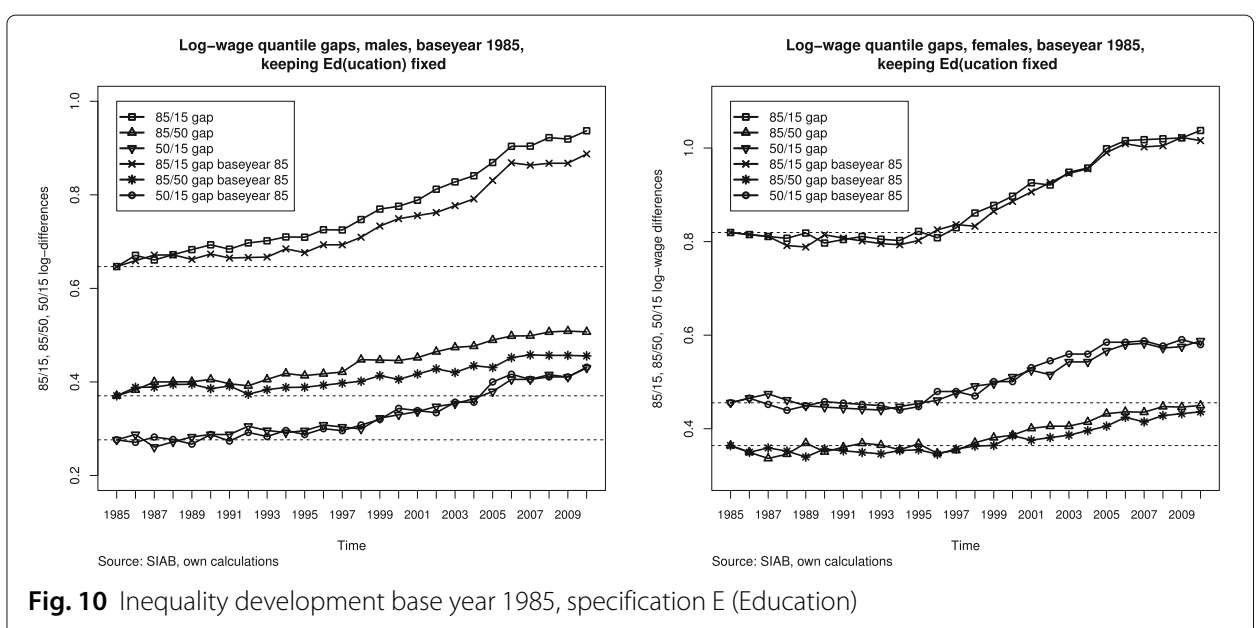

inequality at the bottom of the distribution (as measured by the 50/15 quantile ratio, see lower part of Fig. 10). This means that the compositional effects of the educational expansion mostly affected the upper part but not the lower part of the male wage distribution. The contribution of changes in education on residual wage inequality amounts to a moderate $7.1 \%$, i.e., there is no strong shift towards groups of workers with above-average levels of within-group inequality. As a next step, Fig. 11 extends the reweighting procedure to include changes in work experience (in addition to changes in education). Based on the evidence shown in Fig. 11 (left panel) and Table 4 (columns 4 to 6), the incremental contribution of work experience is very small.

In Fig. 12, we add changes in recent labor market histories to our reweighting procedure. This considerably changes the results, affecting in particular the bottom of the distribution. The incremental contribution amounts to $16.9 \%$ for overall wage inequality and to $19.2 \%$ for lower tail inequality (column 10 of Table 4). This means that increasingly discontinuous labor market histories are important to explain the rise in lower-tail wage inequality. There was also a sizeable contribution to changes in residual wage inequality (10.7\%), suggesting that changes in recent labor market histories were associated with shifts towards worker groups with higher levels of within-group inequality. Finally, Fig. 13 adds changes in occupations and industry structure. This also contributes to the general rise in male wage inequality ( $13.0 \%$ for overall wage inequality, $22.2 \%$ to inequality at the bottom, and $13.6 \%$ to residual wage inequality, see columns 11 to 13 of Table 4).

Note that adding the stage (Occ+Ind) results in the cumulative effect of changing the joint distribution of all our covariates $(\mathrm{Ed}+\mathrm{Ex}+\mathrm{Hist}+\mathrm{Occ}+\mathrm{Ind})$. As shown in column 12 of Table 4, compositional changes explain more than half of the increase in male wage inequality over the period 1985 to 2010 (53.0\% of overall wage inequality, 54.6\%/51.5\% at the top/bottom, $34.0 \%$ of residual wage inequality). Our results confirm the importance of compositional effects for male wage inequality changes also found by Dustmann et al. (2009) and Felbermayr et al. (2014), but establish the contribution of the additional factor of changes in recent labor market histories. Note that the explanatory power of compositional changes is particularly high between 1985 and 1995 (holding characteristics fixed there is no increase in inequality at all, see left panel of Fig. 13), but became somewhat 


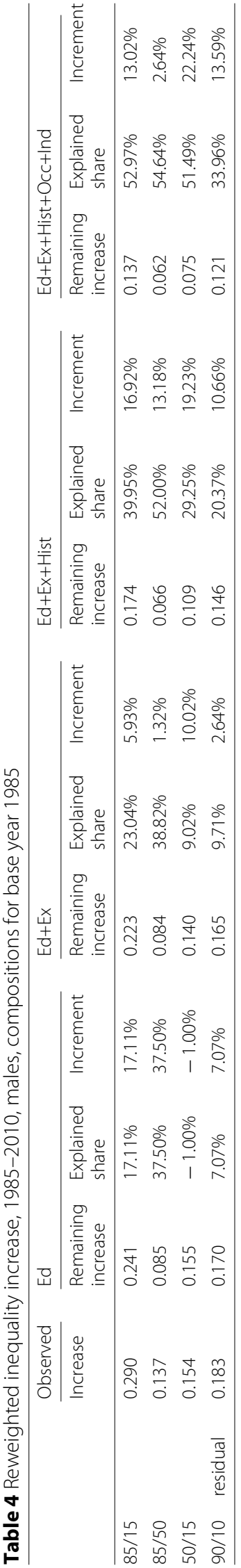




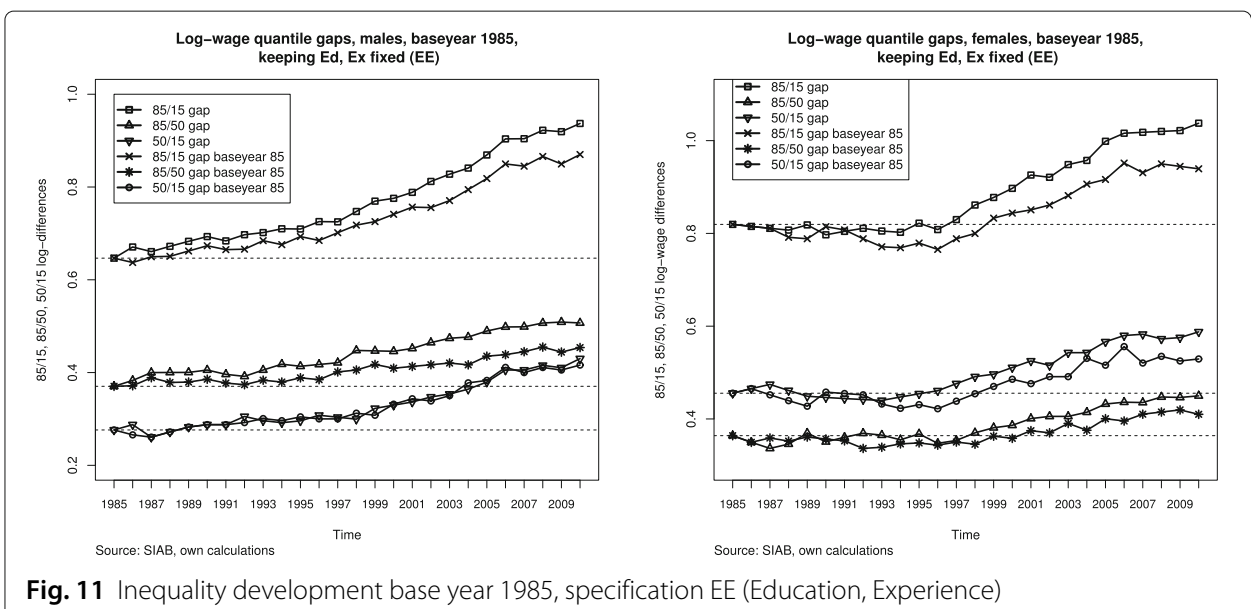

weaker from 1996 onwards. Similar to the findings for the USA (Lemieux 2006), the total contribution of the compositional changes considered lies above $50 \%$, which is quite high. Next, we turn to results for female full-timers, see the right hand panels of Figs. 10, 11, 12 , and 13. By contrast to the findings for males, Fig. 10 shows that the increase in female wage inequality remains largely unchanged, when holding constant the 1985 distribution of education ${ }^{14}$. Adding changes in potential work experience (which are mainly driven by age) yields a strong incremental contribution (35.1\% to overall inequality, $30.4 \%$ to upper half inequality, and $38.2 \%$ to lower half inequality; see Fig. 11 and columns 5 to 7 of Table 5). This also differs from the findings for males. In light of Fig. 8, the findings for females reflect that younger cohorts are much smaller compared to older ones (e.g., the share of females with 0 to 13 years of potential work experience dropped from $30 \%$ in 1985 to $10 \%$ in 2010). This leads to a rising share of older female full-timers with different wage levels and higher within-group inequality.

Adding recent labor market histories again explains a considerable, incremental share (18.6\% for overall inequality and $17.1 \%$ for residual inequality, columns 8 to 10 in Table 5; see also Fig. 12 to the right). Thus, the impact of part-time episodes and labor market
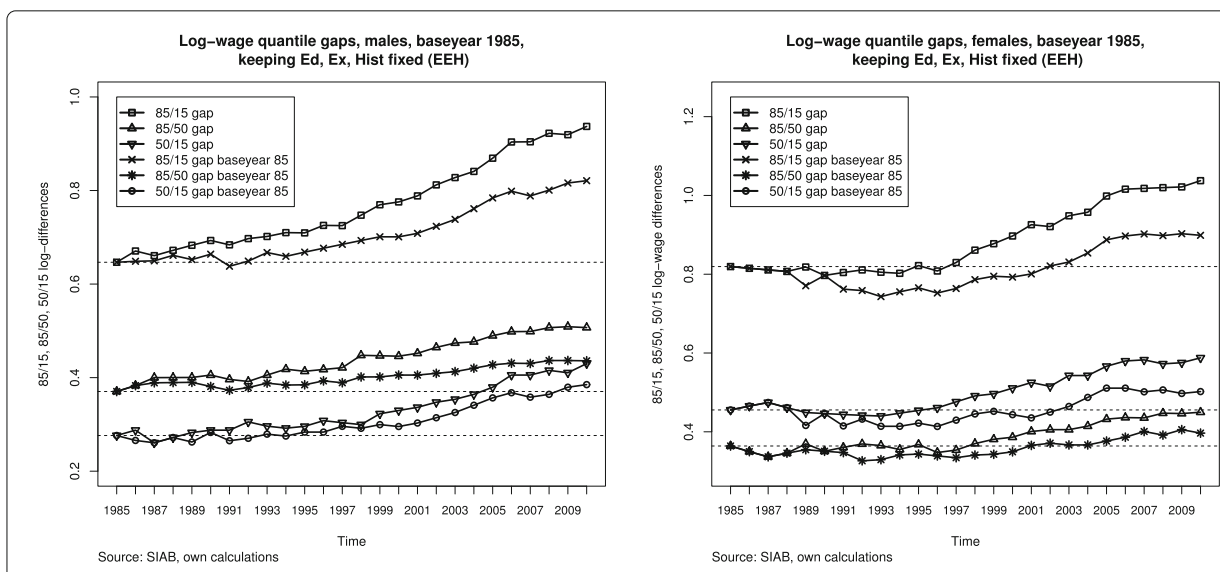

Fig. 12 Inequality development base year 1985, specification EEH (education, experience, labor market history) 


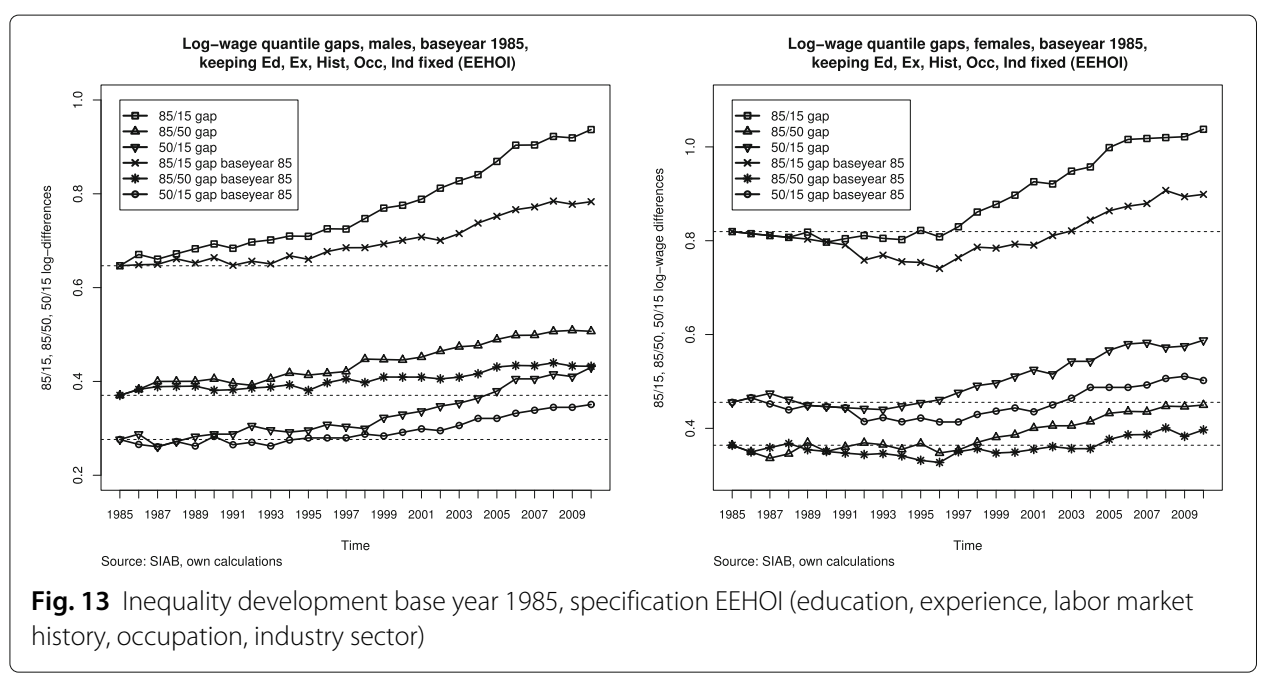

interruptions is similar for males and females. Finally, changes in occupations and industry structure have negligible effects on rising female wage inequality (columns 11 to 13 of Table 5) ${ }^{15}$.

Altogether, we find that compositional changes can account for an even larger share of the rise in female wage inequality than for males. Column 12 of Table 5 shows that $63.6 \%$ of the increase in overall inequality, $61.9 \%$ of the increase in the upper part, and $64.8 \%$ of the increase in the lower part of the distribution can be accounted for by the compositional changes considered. The graph to the right in Fig. 13 implies that, during the period 1991 to 2001, female wage inequality would have fallen even in the absence of compositional changes. An important component has worked through composition changes regarding residual wages, i.e., shifts between groups of workers with different levels of within-group inequality (51.6\% of the changes are accounted for by composition changes; see column 12 of Table 5).

In the Additional file 1, we carry out a robustness check of our analysis that reverses the roles of the base and target years (1985 vs. 2010). With few exceptions, all our findings are robust to the choice of the base year (see Additional file 1 for details).

\subsection{Counterfactual full-time wages for total employment}

This section extends the analysis of full-wage wages to total employment, including those working part-time in the year of observation. As explained above, part-time wages are not comparable because we lack detailed information on hours worked in our data set. However, we do observe the personal characteristics of part-timers, which our analysis of composition effects includes. We consider the distribution of characteristics in the combined sample of full-timers and part-timers ("total employment"), thereby estimating inequality of full-time wages among individuals who are currently employed.

This excercise will be informative in four ways. First, comparing the actual wage distribution of full-timers with the counterfactual wage distribution that assumes that both part-time and full-timers are paid full-time wages will be informative about whether parttimers are a positive or negative selection with respect to their characteristics (compared to full-timers). Second, examining the development of the counterfactual wage distribution for the total employment sample over time may serve as an estimate for composition 


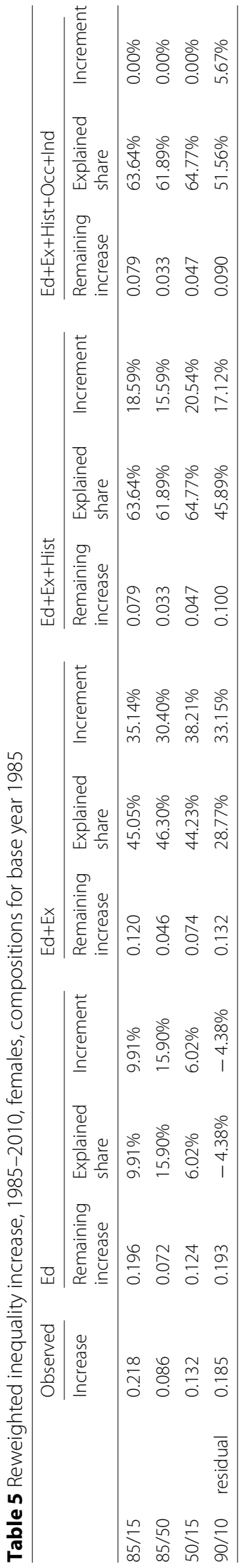


effects on wage inequality in a wider population of part-time and full-timers, which we cannot examine directly given that comparable wage information for part-timers is missing. This also serves as a robustness checks of our above findings for full-timers. Third, the effect of selection into full-time work versus part-time work is mostly accounted for by controlling for the recent employment history. Fourth, we net out selective transitions between part-time and full-time work in our analysis of composition effects, in the sense that we measure composition effects net of such (often temporary) movements between part-time and full-time work.

We start with the estimated counterfactual trends in inequality of full-time wages in a sample sharing the composition of total employment (for a more detailed explanation, see "Composition reweighting for total employment" section in the Appendix). Figure 14 shows the trend in wage inequality if full-timers shared the education composition of total employment. For male workers, the differences between both distributions is very small in 1985. After 2000, we see a slight decline in the $15 \%$ quantile of the total employment distribution relative to the full-time distribution, which leads to slightly wider 50/15 and $85 / 15$ quantile gaps. This suggests a negative selection into part-time work for men. However, the part-time share of male workers already starts rising in the early 1990s, while we only observe negative effects of selection into part-time a decade later. This implies that there is no negative selection associated with the initial expansion of part-time work. Also, for females, the initial full-time and total employment distributions for females are quite similar, especially regarding the upper tail. However, the quantiles diverge quickly and by 1990, we see lower wages for the total employment sample over the entire distribution. This means that characteristics that were prevalent among part-time workers involve lower wage returns than those of full-timers, implying negative selection into parttime work. After 1990, the distributional gap between the full-time and the counterfactual total employment sample was almost constant, implying a stable positive selection into full-time work.

The differences of the observed female full-time wage distribution in 2010 and the wage distribution for the counterfactual total emloyment sample are also shown in the right panel of Fig. 15 (bold vs. dashed line). Considering the total employment sample shifts the distribution to the left, i.e. the full-time sample is positively selected. The dotted lines
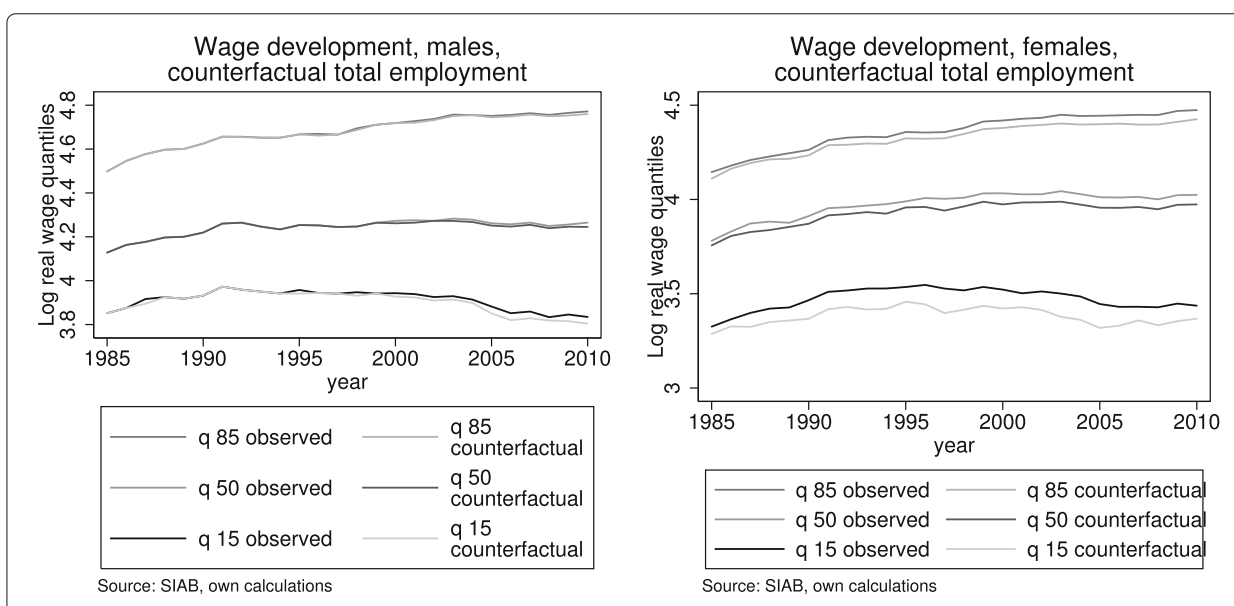

Fig. 14 Counterfactual wage distribution, if full-timers had total employment characteristics 


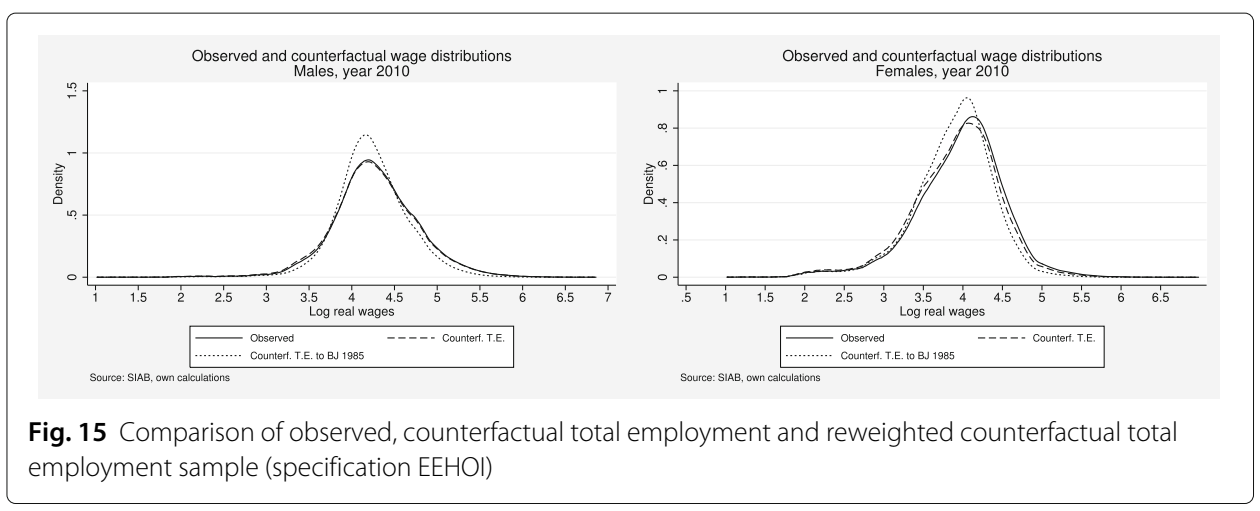

in Fig. 15 represent the wage distributions that result when one further changes the characteristics to those of the total employment sample in 1985. This results in a considerable compression of the wage distribution. Again, changing characteristics contribute to rising inequality.

Table 6 shows the contribution of composition changes for trends in full-time wage inequality in the total employment sample, which are broadly similar to the results for the male full-timers in Table 4. In particular, there is an important role for composition changes regarding education (especially at the top) and labor market histories (especially at the bottom). Including part-timers into the analysis makes the contribution of labor market histories to rising inequality much more pronounced at the bottom of the distribution (38.6\% in Table 6 vs. $22.2 \%$ in Table 4). There is only a limited role for changes in occupations and industries. These conclusions are robust to reversing the base year (see Table 6 and SA4 in the Additional file 1). Table 7 shows the results for the female total employment sample. Despite the much higher part-time share in the female sample, the results in Table 7 are again quite similar to Table 5 for female full-timers. There is a role for shifts in experience and recent labor market histories, while changes in education and occupations and industries do not contribute much. In Table SA5 in Additional file 1, we reverse the base year. As in the female full-time sample, this boosts the role of education changes (particularly at the top of the distribution) and leads to a number of smaller unsystematic changes that point to complex interaction effects of compositional and wage structure effects. Similar to males, extending the analysis to total employment for females also amplifies the importance of recent labor market histories for increasing wage inequality at the bottom of the distribution $(20.5 \%$ vs. $28.6 \%$ in Table 5 vs. Table 7 , and $11.9 \%$ vs. $22.7 \%$ in Additional file 1: Table SA7 vs. Additional file 1: Table SA5, column 10).

\section{Conclusions}

This paper scrutinizes the contribution of composition changes in education, potential work experience, labor market history, industry structure, and occupation on the rise in inequality of full-time wages in Germany from 1985 until 2010. We account explicitly for the growing importance of employment interruptions and temporary part-time episodes among full-time workers, and we estimate the counterfactual full-time wage distribution for all employees. 


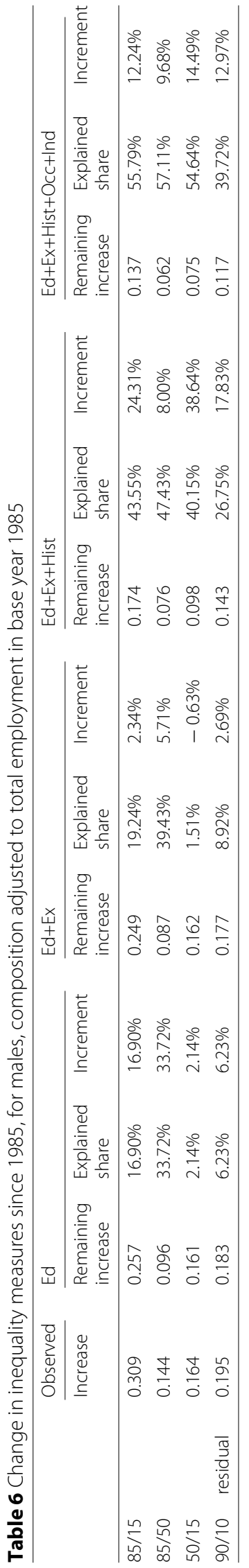




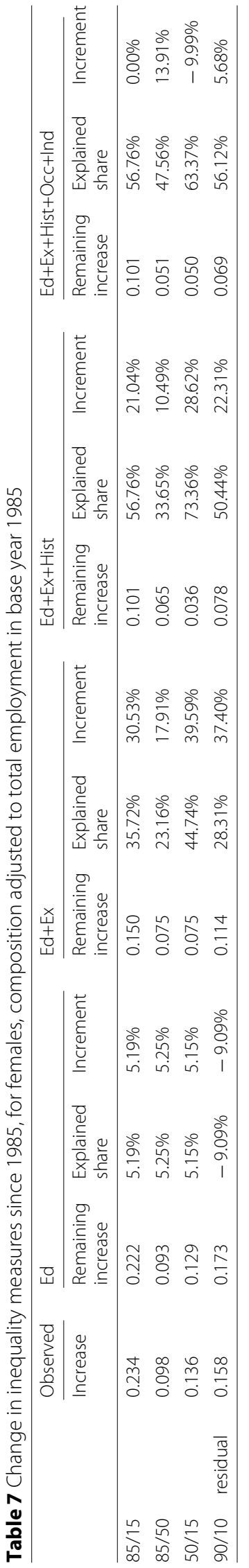


Our results imply that changes in observables account for a large part of the rise in wage inequality and that the the growing importance of employment interruptions and temporary part-time episodes play an important role for wage inequality among full-time workers. For males, we find that (depending on the base year) 43 to $53 \%$ of the rise in wage inequality between 1985 and 2010 can be explained by compositional effects of the observables considered. For females, the importance of composition changes is even higher, ranging between 64 and $78 \%$. To the best of our knowledge, the literature has so far not recognized the strong role of composition effects for the rise of female wage inequality. For males, composition changes in education (especially in the upper part of the distribution) and changes in recent labor market histories (especially in the lower part of the distribution) are the main contributors to compositional change. The compositional effects of male labor market histories to rising overall wage inequality range from 14 to $17 \%$, and from 18 to $23 \%$ in the lower half of the distribution. For females, we find strong composition effects of changes in age/experience and in recent labor market histories. The latter contribute 17 to $18 \%$ to the overall increase in female wage inequality over the period 1985 to 2010. When including part-timers, the role of recent labor market histories becomes even stronger.

Our results are policy relevant because both changes in the age/education structure and in labor market histories are observable and to a certain extent predictable. One might wonder to what extent the contribution of increasing heterogeneity in recent labor market histories is causal or to what extent these are just proxies for unobservables. Still, while we are not in a position to separate between these two explanations, accounting for labor market history in fact also proxies for remaining unobservable differences in employment outcomes. Furthermore, the observed trends in previous part-time work and employment interruptions are very strong, which suggests that observed changes in labor market history are mostly the intended consequences of policy changes (Section 3.2). It is well documented in the literature that part-time work and previous nonemployment have effects on subsequent wages, even when controlling for unobservables (Arulampalam 2001; Schmieder et al. 2010; Paul 2016; Blundell et al. 2016). We therefore expect trends in these variables to directly change the wage distribution in subsequent periods. We also note that our base and target years (1985 and 2010) represent similar points in the business-cycle so that our analysis is unlikely to be affected by huge differences with respect to this aspect. Finally, we note that even if the observed changes in previous part-time work and nonemployment involve increased sorting in terms of unobservables across individuals with differing labor market histories, this would still make histories very relevant factors as their direct effect would be enhanced by changes in unobservables.

\section{Endnotes}

${ }^{1}$ There is a large literature on the rise of wage inequality in Germany, see, e.g., Dustmann et al. (2009), Antonczyk et al. (2010), Card et al. 2013 as well as the literature review in Section 2.

${ }^{2}$ There is a cyclical component in transitions from nonemployment and part-time employment to full-time employment. During an upswing (downturn), one would expect these to increase (fall). In a recent study, Borowczyk-Martins and Lalé (2018) show that 
for the UK and the USA transitions from part-time to full-time employment at the same employer are a major driver of the cyclical changes in part-time employment, growing (declining) during an upswing (downturn). Our analysis focuses on the long-term rise in the share of full-timers with nonemployment and part-time experience. As our empirical results show, this long-term rise dominates the cyclical variation.

${ }^{3}$ See, e.g. Arulampalam (2001), Burda and Mertens (2001), Beblo and Wolf (2002), Manning and Petrongolo (2008), Edin and Gustavsson (2008), Schmieder et al. (2010), Edler et al. (2015), or Paul (2016).

${ }^{4}$ See also (in chronological order) Kohn (2006), Gernandt and Pfeiffer (2007), Antonczyk et al. (2010), Fitzenberger (2012), Card et al. (2013), Felbermayr et al. (2014), Dustmann et al. (2014), Riphahn and Schnitzlein (2016), Möller (2016), and Antonczyk et al. (2018). Most recent studies are based on administrative employment records in the Sample of Integrated Employment Biographies (SIAB) - or on earlier versions of the same data source - as provided by the Research Data Center of the IAB and the Federal Employment Agency. Some studies use of the cross-sectional wage surveys in the German Structure of Earnings Survey (GSES) provided by the Research Data Center of the Statistical Offices, the Socio-Economic Panel (GSOEP) provided by DIW or the BIBB-IAB/Bibb-BAuA Labor Force Surveys (BLFS). While the SIAB data only involves earnings, the GSES, the GSOEP, and the BLFS allow for an analysis of hourly wages. Researchers using the SIAB data typically focus on full-time working employees. While the SIAB and the GSOEP provide panel data, the GSES data and the BLFS only involve repeated cross-sections every four to six years and the GSES surveys before 2010 only involve a subset of all industries and they lack very small firms. Compared to the GSOEP and the BLFS, the GSES and the SIAB provide much larger cross-sections on employees and wages. All four data sets document the rise in wage inequality since the mid 1990s, see Dustmann et al. (2009, SIAB), Fitzenberger (2012, SIAB and GSES), Antonczyk et al. (2009, BFLS), and Gernandt and Pfeiffer (2007, GSOEP).

${ }^{5}$ The recent study by Möller (2016) shows that the rise in wage inequality stopped in 2010 based on a new release of the SIAB data. However, the comparison of the years before and after 2011 is plagued by a structural break in 2011 regarding the distinction between part-timers and full-timers. For both reasons, we abstain from analyzing the SIAB data after 2010 since our focus is on analyzing the rise in wage inequality.

${ }^{6}$ This study uses the factually anonymous Sample of Integrated Labour Market Biographies (version 1975 - 2010). Data access was provided via a Scientific Use File supplied by the Research Data Centre(FDZ) of the German Federal Employment Agency (BA) at the Institute for Employment Research (IAB), see vom Berge et al. (2013) for a data documentation.

${ }^{7}$ We have calculated the standard deviation of hours of work for the years 1985 and 2010 based on the German Socioeconomic Panel (detailed results are available upon request). For part-timers, the standard deviation is two to three times higher than for full-timers.

${ }^{8}$ In order to clearly separate previous part-time and nonemployment during educational spells from those after having completed education, we also include the evidence for full-timers aged at 30 to 60 years old, see Figs. 16 and 17 in the Appendix. For part-time experience, the trends are very similar for the 25 to 60 years old and the 30 to 60 years old. 
${ }^{9}$ In Table SA2 in the Additional file 1, we show that differences in means and variances below and above the median are highly statistically significant.

${ }^{10}$ We thank an anonymous referee for raising these issues.

${ }^{11}$ Unfortunately, the SIAB data do not record whether a nonemployment episode is due to an educational spell. However, the data involve the educational degree as possible outcome of a previous nonemployment episode.

12 This method has been applied, among others, by Lemieux (2006) and Dustmann et al. (2009). For an overview of alternative decomposition techniques, see Fortin et al. 2011.

${ }^{13}$ Such an analysis ignores general equilibrium effects, i.e., changes in the conditional wage structure are assumed to be independent of changes in the work force composition.

${ }^{14}$ However, there is a slight difference with regard to the effect of female education when we take as the base year 2010 instead of 1985 . This points to interaction effects. We carry out this reverse analysis in section Section SA1.2 in the Additional file 1.

${ }^{15}$ It is not an error that quantile gaps for the overall distribution are unchanged up to the third digit in row 13 of Table 5 when adding occupation and industry characteristics. This is due to the fact that daily wages are rounded to full Euros and quantiles only change if the change in counterfactual weights is large enough to move the quantile value to a different Euro integer.

${ }^{16}$ Compare the discussion in Card et al. (2013).

\section{Appendix}

\section{Additional figures}

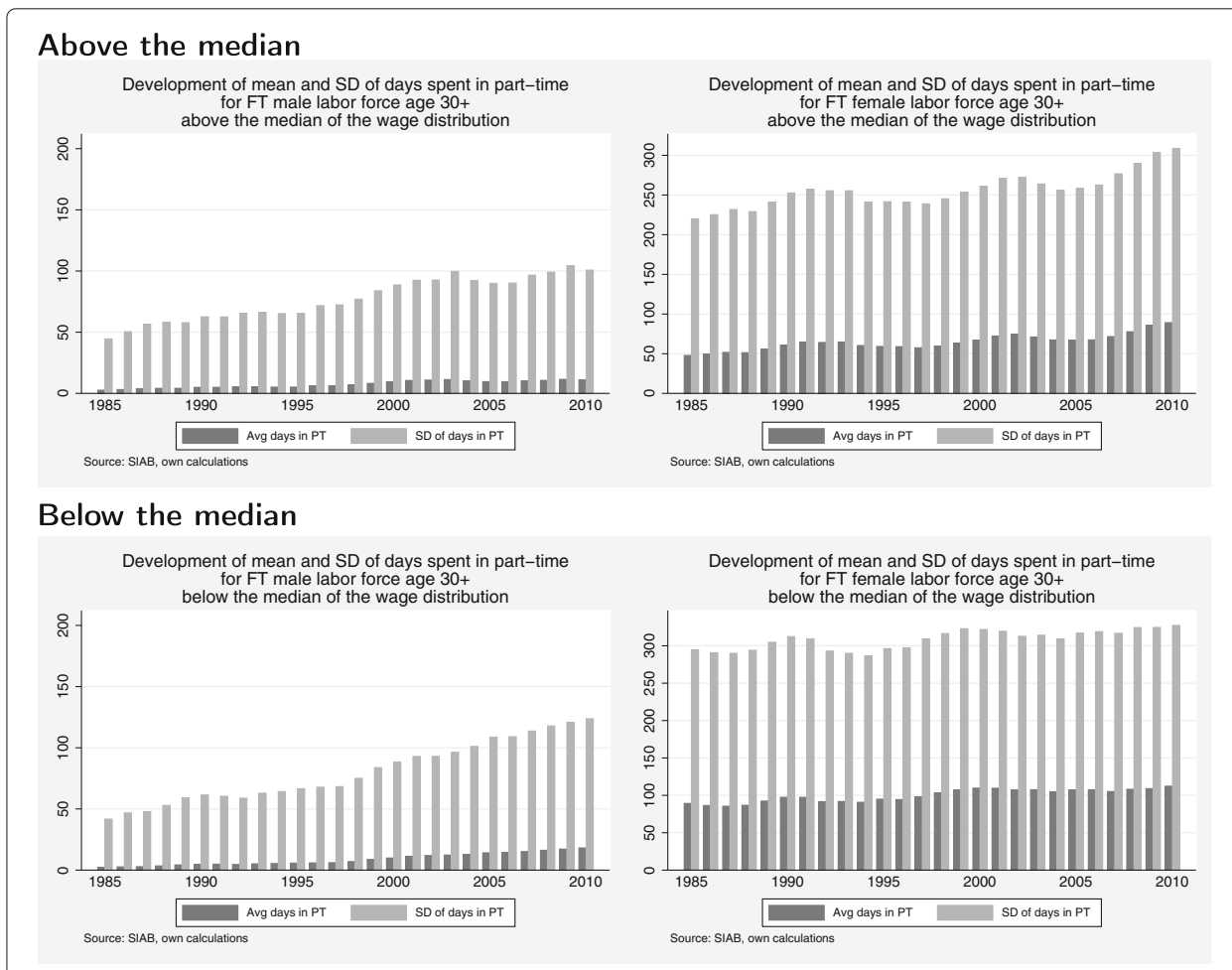

Fig. 16 Days spent in part-time work during the last 5 years (full-timers aged 30-60 years) 


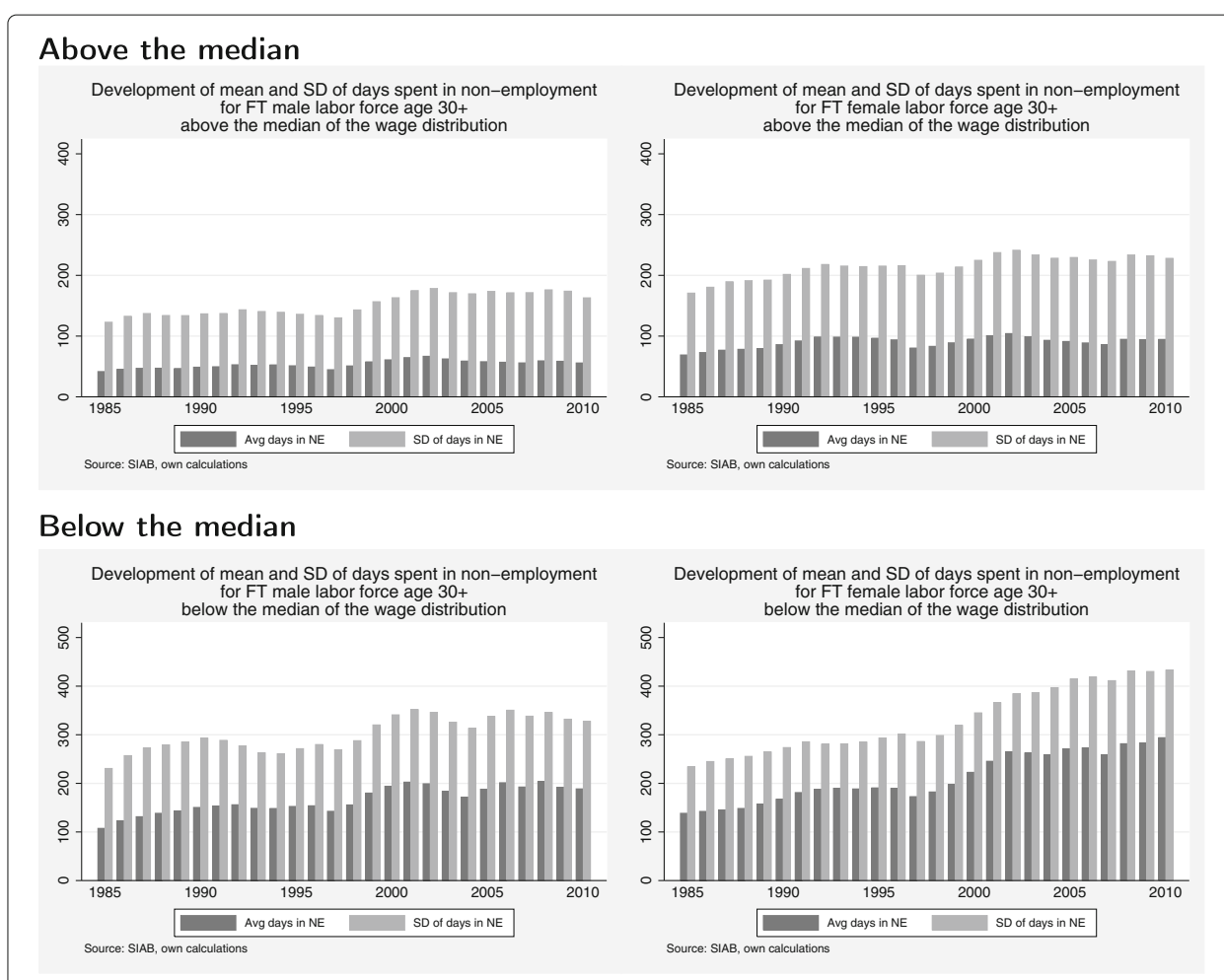

Fig. 17 Days spent in nonemployment during the last 5 years (full-timers aged 30-60 years)

\section{Imputation of wages above censoring threshold}

Our imputation procedure for wages above the contribution threshold of social security is loosely based on Gartner (2005). We assume that log-wages are approximately normally distributed and estimate expected wages above the censoring point with a Tobit model. We regress log wages on education, age, nationality, and individual labor market history, separately for both genders. Results in the literature suggest that this type of imputation leads to a slight upward bias in the variance of wages each year. Important for our analysis, however, it does not lead to bias in the trend of wage dispersion ${ }^{16}$. As we want to take into account that the variance of wages is potentially correlated with individual characteristics, we modify the procedure suggested by Gartner (2005) to explicitly model a heteroscedastic variance for the Tobit regression. A simple imputation of log wages from the Tobit model would exhibit too little variation. We therefore adjust imputed wages by a random draw from a truncated normal distribution, using the predicted heteroscedastic variance from the Tobit model. We impute separately for each year and for male and female workers. Imputation by this method raises the mean wage by $0.8 \%$ and the standard deviation $14.6 \%$ for males, and by $0.2 \%$ as well as $3.2 \%$ for females across all years.

\section{Details of counterfactual analysis} Composition reweighting for full-timers

We account for the selection into full-time work based on the observed composition of workers regarding their socio-economic characteristics. Changes in the composition over time reflect selective movements of individuals into and out of full-time work. Our aim is 
to quantify the effects of such changes in the composition of full-timers on wage inequality. We use the reweighting methodology introduced by DiNardo et al. (1996) to estimate counterfactual wage distributions fixing the composition of a reference group (in our case the population of full-timers in a reference year).

In the first part of our analysis, we analyze the distribution of full-time wages which would result if the distribution of worker characteristics had not changed over time but only the conditional wage structure (i.e., the wage distribution holding characteristics constant). Based on these counterfactual wage distributions, we calculate and compare the development of inequality as measured by the gaps between the 85 th, 50 th, and 15 th wage percentiles and the spread of residual wages. We take the residuals from a Mincer regression of log wages $w$ on a flexible specification of the characteristics listed in Table 1. The dispersion of residual wages represents wage inequality within narrow groups of workers defined by the characteristics given in Table 1. Changes in residual wage inequality may also be the result of changes in the composition of the labor force (Lemieux 2006). This will be the case if there is heteroscedasticity, i.e., the conditional residual variance depends on observed characteristics. In this case, shifts in the distribution of characteristics affect residual wage inequality. For instance, overall residual wage inequality will typically rise if there is a rising share of workers with above-average levels of within-group inequality.

Let $t_{x}=b$ denote the base year, for which the composition of the work force will be held fixed, and $t_{w}=o$ the year for which we intend to estimate a counterfactual wage distribution. We call this year the observation year. Here, we only use observations on full-timers in years $t_{w}$ and $t_{x}$. The counterfactual wage distribution using the conditional wage structure of year $t_{w}=o$ but the distribution of characteristics $x$ from the base year $t_{x}=b$ is given by

$$
\begin{aligned}
f\left(w \mid t_{w}=o, t_{x}=b\right) & =\int_{x} f\left(w \mid x, t_{w}=o\right) d F\left(x \mid t_{x}=b\right) \\
& =\int_{x} f\left(w \mid x, t_{w}=o\right) \rho\left(t_{x}=b\right) d F\left(x \mid t_{x}=o\right) .
\end{aligned}
$$

where $f\left(w \mid t_{w}=o, t_{x}=o\right)$ is the actual density of wages for characteristics $x$ in year $t_{w}=o$ and $\rho\left(t_{x}=b\right)=\frac{d F\left(x \mid t_{x}=b\right)}{d F\left(x \mid t_{x}=o\right)}$ is the reweighting factor which translates the density of observed wages into the counterfactual density. Note that as a special case $f\left(w \mid t_{w}=\right.$ $\left.o, t_{x}=o\right)=\int_{x} f\left(w \mid x, t_{w}=o\right) d F\left(x \mid t_{x}=o\right)$, for which $\rho\left(t_{x}=b\right) \equiv 1$ in Eq. (1). The reweighting factor can be written as the ratio $\rho\left(t_{x}=b\right)=\frac{P(t=b \mid x)}{P(t=o \mid x)} \frac{P(t=o)}{P(t=b)}$, where $P(t=o)$ and $P(t=b)$ are the sample proportions of the observation year and the base year when pooling the data for both years.

The proportions $P(t=b \mid x)$ and $P(t=o \mid x)$ are estimated by logit regressions of the respective year indicator on flexible specifications of the characteristics shown in Table 1. The logit regressions are based on the sample pooling the base year and the observation year. Using the fitted logit probabilities, we then calculate the individual reweighting factors $\rho_{i}\left(t_{x}=b\right)$ for observations $i$. All our estimates use the sample weights $s_{i}$ which compensate for the varying length of employment spells. For robustness reasons, we trim the maximum value of individual observation weights to the value of 30 , in order to prevent extreme values of the reweighting factor, which may occur as a result of extremely rare combinations of characteristics. We tested a range of trimming thresholds and found 
that values between 20 and 50 avoid extreme outliers, while at the same time excluding a very small number of observations (details are available upon request).

The reweighting factor can be incorporated into the estimation of counterfactual quantiles based on the sample wage distribution while fixing the composition of full-timers in the base year. Using the abbreviation $\rho=\rho\left(t_{x}=b\right)$, the reweighted (composition adjusted) $p \%$ quantile is given by

$$
Q_{p}\left(w \mid t_{w}=o, t_{x}=b\right)= \begin{cases}\frac{w_{[j-1]}+w_{[j]}}{2} & \text { if } \sum_{i=1}^{j-1}(s \rho)_{[i]}=\frac{p}{100} \sum_{i=1}^{n}(s \rho)_{[i]} \\ w_{[j]} & \text { otherwise }\end{cases}
$$

where

$$
j=\min \left(k \mid \sum_{i=1}^{k}(s \rho)_{[i]}>\frac{p}{100} \sum_{i=1}^{n}(s \rho)_{[i]}\right),
$$

$w_{[i]}$ is the $i$ th order statistic of wages and $(s \rho)_{[i]}$ is defined accordingly (i.e., the order statistic of the compound individual weights $s \rho$, combining the sample weight $s$ with the reweighting factor $\rho$ ).

We consider the quantile gaps (differences in quantiles of log wages) between the 85th and 50 th, the 85 th and 15 th as well as the 50 th and 15 th counterfactual percentile, i.e.

$$
\begin{aligned}
& Q G_{85 / 50}\left(w \mid t_{w}=o, t_{x}=b\right)=Q_{85}\left(w \mid t_{w}=o, t_{x}=b\right)-Q_{50}\left(w \mid t_{w}=o, t_{x}=b\right) \\
& Q G_{85 / 15}\left(w \mid t_{w}=o, t_{x}=b\right)=Q_{85}\left(w \mid t_{w}=o, t_{x}=b\right)-Q_{15}\left(w \mid t_{w}=o, t_{x}=b\right) \\
& Q G_{50 / 15}\left(w \mid t_{w}=o, t_{x}=b\right)=Q_{50}\left(w \mid t_{w}=o, t_{x}=b\right)-Q_{15}\left(w \mid t_{w}=o, t_{x}=b\right) .
\end{aligned}
$$

In addition to a graphical comparison of the actual and counterfactual development over time, we also contrast the increase in the counterfactual quantile gaps with the actual increase between 1985 and 2010. This allows us to quantify the share of the increase in inequality associated with composition changes (where $g \in\{85 / 50,85 / 15,50 / 15\}$ )

$$
\begin{aligned}
& \text { shareQ } G_{g, x}\left(w \mid t_{w}=2010, t_{x}=1985\right)= \\
& \frac{Q G_{g}\left(w \mid t_{w}=2010, t_{x}=2010\right)-Q G_{g}\left(w \mid t_{w}=2010, t_{x}=1985\right)}{Q G_{g}\left(w \mid t_{w}=2010, t_{x}=2010\right)-Q G_{g}\left(w \mid t_{w}=1985, t_{x}=1985\right)} .
\end{aligned}
$$

For the logit regression, we use a sequence of specifications adding covariates in order to investigate the incremental composition effect on wage inequality. We divide the vector of characteristics into five groups of variables, namely educational outcomes (Ed), labor market experience (Ex), labor market history (Hist), occupation and industry characteristics (Occ, Ind) (see Tables 1 and 8). Among those, we consider potential labor market experience as continuous and all other variables as categorial, leading to a highly flexible specification of the logit model. We calculate four versions of the counterfactual quantile gaps, starting with a specification only controlling for education (row E in Table 8).

Sequentially adding sets of covariates (characteristics) to our reweighting procedure, we estimate the change in the counterfactual quantile gaps that is associated with the set of covariates considered so far. This way, we quantify the incremental contribution of covariatess to the rise in wage inequality (this contribution is given by the figures in the 
Table 8 Specification overview

\begin{tabular}{|c|c|c|}
\hline Label & Covariates & Specific covariates \\
\hline$E$ & Education & ed \\
\hline EE & Education, Experience & $e d, e x, e d * e x, e x^{2}, e d * e x^{2}$ \\
\hline $\mathrm{EEH}$ & Education, Experience, Labor market history & $\begin{array}{l}e d, e x, e d * e x, e x^{2}, e d * e x^{2}, p t, f t, p t 5, f t 5, e d * \\
p t 5, e d * f t 5, p t 5^{2}, f t 5^{2}, e d * p t 5^{2}, e d * f t 5^{2}\end{array}$ \\
\hline $\mathrm{EEHOI}$ & $\begin{array}{l}\text { Education, Experience, Labor market history, } \\
\text { Occupation \& Industry }\end{array}$ & $\begin{array}{l}e d, e x, e d * e x, e x^{2}, e d * e x^{2}, p t, f t, p t 5, f t 5, e d * \\
p t 5, e d * f t 5, p t 5^{2}, f t 5^{2}, e d * p t 5^{2} \text {,ed * } \\
f t 5^{2}, o c c, o c c * e x, o c c * e x^{2}, \sec , \sec * e x, \sec * \\
e x^{2}, \sec * e d\end{array}$ \\
\hline
\end{tabular}

Covariates used for reweighting procedure. For example, ed, ex, ed $* e x, e x^{2}, e d * e x^{2}$ reads that education, experience, experience-squared and the two interactions education* ${ }^{*}$ experience and exducation*experience-squared are used

columns labeled "Increment"; see, e.g., Table 4). We decompose the difference between the observed and counterfactual rise in inequality into the effects of separate sets of covariates. For example, when adding occupation and industry characteristics (OI) to the reweighting function that already contains education, experience and labor market history $(\mathrm{EEH})$, we measure the incremental effect of occupation and industry (OI) net of the effect contributed by the set of covariates already included (EEH). We add covariates in the order given in Table 8. The incremental effect of each set of covariates depends upon the order in which they are added to the model. Our reasoning behind the choice of the sequence shown in Table 8 is that we gradually move from exogenous and predetermined characteristics towards characteristics that are the likely consequence of endogenous decisions of the individual. We start with education because education typically remains fixed after labor market entry. Next, potential work experience is a linear function of time and education. Similary, labor market history involves characteristics which are affected by education and actual work experience. Finally, occupation and industry can in principle be changed any time conditional on education, experience and labor market history, and we are particularly interested as to whether occupation and industry play a role after accounting for all other individual level characteristics.

One may wonder how the reweighting method deals with endogeneity, i.e., unobservables that are not included in the analysis but that are potentially correlated with the included observables. Fortin et al. (2011) show that for a causal interpretation one only has to make the assumption that the distribution of unobservables for workers with identical observables (including observed labor market history) is the same in the base year and the target year (assumption 5, p. 21 in Fortin et al. 2011). Note that this does not rule out correlation of observables and unobservables. Put differently, the relationship between observables and unobservables is assumed to be time-invariant. This assumption would be violated, if, e.g., having prior part-time/nonemployment experience is increasingly associated with good or bad unobservables. While we cannot rule out this possibility, there is no evidence for such an effect. However, the point to be stressed is that a mere correlation between observables and unobservables does not pose a problem to our method as long as the correlation does not vary systematically over time.

\section{Composition reweighting for total employment}

The reweighting can be expanded to take into account selection between full-time work and total employment based on observables, thus addressing the limitation that the SIAB 
Table 9 Specification for counterfactual total employment

\begin{tabular}{ll}
\hline Variables & Specific covariates \\
\hline Education, experience, labor market history, & ed, ex, ed $*$ ex, ex ${ }^{2}, e d * e x^{2}, p t, f t, p t 5, f t 5, e d *$ \\
occupation, Industry & $p t 5, e d * f t 5$, occ, occ $*$ ex, occ $* e x^{2}, \sec , \sec *$ \\
& $e x, \sec * e x^{2}, \sec *$ ed
\end{tabular}

Covariates used for reweighting procedure

data do not provide comparable wages for part-timers. We first calculate wage distributions for full-timers using the distribution of characteristics in the total employment sample, involving both part-timers and full-timers. Then, in a second step, we reweight these counterfactual wage distribution to the characteristics of a base year, analogous to "Composition reweighting for full-timers" section. The resulting distribution can be interpreted as the wages that would have prevailed had all individuals worked full-time and had their characteristics stayed at the level of the base year.

The first step consists in within-period composition reweighting. We calculate counterfactual wage distributions, which would have prevailed if all individuals had been paid full-time wages. This interpretation holds under the assumption that returns to characteristics for non-full-timers are equal to those for full-timers. The results of Manning and Petrongolo (2008) suggest that hourly wage differentials for (female) part-timers in industrialized countries are not driven by differences in returns to characteristics, which lends credibility to our approach. In order to calculate these distributions, we apply the reweighting technique described in Section 4.1, but instead of the full-time sample in a specific base year, the reference group is total employment in the same year. Let $e \in\{F T, T E\}$ describe the employment group to which each observation belongs, where $F T$ represents full-timers and TE total employment. Full-time workers appear in both FT and TE. The reweighting factor $\rho\left(F T \rightarrow T E, t_{x}=o\right)$ is the probability of characteristics $x$ in the total employment sample in a given year, relative to the probability $x$ in the full-time sample of the same year

$$
\rho\left(F T \rightarrow T E, t_{x}=o\right)=\frac{d F\left(x \mid e_{x}=T E, t_{x}=o\right)}{d F\left(x \mid e_{x}=F T, t_{x}=o\right)}=\frac{P(e=T E \mid x, t=o)}{P(e=F T \mid x, t=o)} \frac{P(e=F T \mid t=o)}{P(e=T E \mid t=o)} .
$$

Then, the counterfactual distribution of wages, assuming the entire labor force was working full-time, can be written as:

$$
\begin{aligned}
& f\left(w \mid e_{w}=F T, e_{x}=T E, t_{w}=o, t_{x}=o\right) \\
= & \int_{x} f\left(w \mid x, e_{w}=F T, t_{w}=o, t_{x}=o\right) \rho\left(F T \rightarrow T E, t_{x}=o\right) d F\left(x \mid e_{x}=F T, t_{x}=o\right) .
\end{aligned}
$$

Here, $P(e=T E \mid x, t=o)$ is estimated by a weighted logit regression on the pooled sample of the reference group (total employment $T E$ ) and the group of interest (full-timers $F T$ ), with the employment status indicator $e$ denoting group membership of each observation. In this step, we use the specification from Table 9, in order to include the full set of observable individual characteristics.

In a second step, we analyze the distribution of wages which would have prevailed, had all employees worked full-time, and had their characteristics been fixed at the level of the 
base year. By holding the composition of total employment constant over time, we control for changes in the wage distribution due to changes in the selection into total employment over time. This counterfactual distribution can be written as:

$$
\begin{gathered}
f\left(w \mid e_{w}=F T, e_{x}=T E, t_{w}=o, t_{x}=b\right)= \\
\int_{x} f\left(w \mid x, e_{w}=F T, t_{w}=o\right) \rho\left(e_{x}=T E, t_{x}=b\right) \rho\left(F T \rightarrow T E, t_{x}=o\right) d F\left(x \mid e_{x}=F T, t_{x}=o\right),
\end{gathered}
$$

where

$$
\rho\left(e_{x}=T E, t_{x}=b\right)=\frac{d F\left(x \mid e_{x}=T E, t_{x}=b\right)}{d F\left(x \mid e_{x}=T E, t_{x}=o\right)}=\frac{P\left(t=b \mid x, e_{x}=T E\right)}{P\left(t=o \mid x, e_{x}=T E\right)} \frac{P(t=o \mid e=T E)}{P(t=b \mid e=T E)}
$$

Analogous to "Composition reweighting for full-timers" section, we sequentially add groups of covariates to our logit specifications as described by Table 8 . This allows us to investigate the incremental changes in inequality associated with the corresponding composition changes.

\section{Additional file}

Additional file 1: Supplementary appendix. (PDF $320 \mathrm{~kb}$ )

\section{Acknowledgements}

We are grateful to the Research Data Center at IAB for useful discussions. We thank Benjamin Bruns, Christian Dustmann, Uta Schönberg, Alexandra Spitz-Oener, and various seminar audiences for the helpful comments and suggestions. We would also like to thank the anonymous referees and the editor for the useful remarks.

Responsible editor: Pierre Cahuc

\section{Funding}

This study was funded by the German Science Foundation (DFG) through the project "Accounting for Selection Effects in the Analysis of Wage Inequality in Germany" (grant number: BI 767/3-1 and FI 692/16-1).

\section{Availability of data and materials}

Our empirical analysis uses a scientific use file of German adminstrative employment records (see vom Berge, P., A. Burghardt, S. Trenkle, 2013). These data are confidential and can be accessed through the RDC of IAB/BA in Nuremberg.

\section{Competing interests}

The IZA Journal of Labor Economics is committed to the IZA Guiding Principles of Research Integrity. The authors declare that they have observed these principles.

\section{Publisher's Note}

Springer Nature remains neutral with regard to jurisdictional claims in published maps and institutional affiliations.

\section{Author details}

${ }^{1}$ University of Tübingen, Tübingen, Germany. ${ }^{2}$ IZA, Bonn, Germany. ${ }^{3}$ Humboldt University Berlin, Berlin, Germany. ${ }^{4}$ IFS, London, UK. ${ }^{5}$ CESifo, Munich, Germany. ${ }^{6}$ ROA, Maastricht, Netherlands. ${ }^{7}$ ZEW, Mannheim, Germany.

Received: 14 June 2018 Accepted: 24 October 2018

Published online: 28 November 2018

\section{References}

Acemoglu D, Autor D (2011) Skills, tasks and technologies: implications for employment and earnings. In: Ashenfelter $\mathrm{O}$ Card D (eds). Handbook of Labor Economics, vol 4b, ch. 12, North Holland, Amsterdam

Antonczyk D, Fitzenberger B, Leuschner U (2009) Can a task-based approach explain the recent changes in the German wage structure? J Econ Stat 229:214-238

Antonczyk D, Fitzenberger B, Sommerfeld K (2010) Rising wage inequality, the decline in collective bargaining, and the gender wage gap. Labour Econ 17:835-847 
Antonczyk D, DeLeire T, Fitzenberger B (2018) Polarization and rising wage inequality: comparing the U.S. and Germany. Econometrics 6. https://doi.org/10.3390/econometrics6020020

Arulampalam W (2001) Is unemployment really scarring? Effects of unemployment experiences on wages. Econ J 111:F585-F606

Autor D, Levy F, Murnane R (2003) The skill content of recent technological change: an empirical exploration. Q J Econ 118:1279-1333

Autor D, Katz LF, Kearney MS (2008) Trends in US wage inequality: revising the revisionists. Rev Econ Stat 90:300-323

Autor D (2013) The 'task approach' to labor markets: an overview. J Labour Mark Res 46:185-199

Beblo M, Wolf E (2002) How much does a year off cost? Estimating the wage effects of employment breaks and part-time periods. Cah Economiques Brux 45(2):191-217

Biewen M, Seckler M (2017) Changes in the German wage structure: unions, internationalization, tasks, firms, and worker characteristics. IZA Discussion Paper No. 10763. IZA Institute of Labor Economics, Bonn

Blundell R, Dias MC, Meghir C, Shaw JM (2016) Female labor supply, human capital, and welfare reform. Econometrica 84:1705-1753

Borowczyk-Martins D, Lalé E (2018) The Ins and Outs of Involuntary Part-time Employment. IZA Discussion Paper No. 11826. IZA Bonn

Burda M, Mertens A (2001) Estimating wage losses of displaced workers in Germany. Labour Econ 8:15-41

Burda M, Hunt J (2011) What Explains the German Labor Market Miracle in the Great Recession? Brook Pap Econ Act 42:273-335

vom Berge P, Burghardt A, Trenkle S (2013) Sample of integrated labour market biographies regional file 1975-2010 (SIAB-R 7510). FDZ data report, 09/2013, Nuremberg

Card D, Heining J, Kline P (2013) Workplace heterogeneity and the rise of West German wage inequality. Q J Econ 128:967-1015

Connolly S, Gregory M (2009) The part-time penalty: earnings trajectories of British women. Oxf Econ Pap 61:76-97

DiNardo J, Fortin NM, Lemieux T (1996) Labour market institutions and the distribution of wages. Econometrica 64:1001-1044

Dustmann C, Ludsteck J, Schönberg U (2009) Revisiting the German wage structure. Q J Econ 124:843-881

Dustmann C, Fitzenberger B, Schönberg U, Spitz-Oener A (2014) From sick man of Europe to economic superstar: Germany's resurgent economy. J Econ Perspect 28:167-188

Edin PA, Gustavsson M (2008) Time out of work and skill depreciation. Ind Labor Relat Rev 61:163-180

Edler S, Jacobebbinghaus P, Liebig S (2015) Effects of unemployment on wages: differences between types of reemployment and types of occupation. SFB 882 Working Paper Series No. 51. University of Bielefeld, Bielefeld

Felbermayr G, Baumgarten D, Lehwald S (2014) Increasing wage inequality in Germany: what role does global trade play? In: Glob Econ Dyn Bertelsmann Stiftung

Fitzenberger B (1999) Wages and employment across skill groups: an analysis for West Germany. Physica/Springer, Heidelberg

Fitzenberger B (2012) Expertise zur Entwicklung der Lohnungleichheit in Deutschland. Arbeitspapier, Sachverständigenrat zur Begutachtung der Gesamtwirtschaftlichen Entwicklung, Wiesbaden

Fitzenberger B, Osikominu A, Völter R (2006) Imputation rules to improve the education variable in the IAB employment subsample. J Appl Soc Sci Stud (Schmollers Jahrbuch) 126:405-436

Fitzenberger B, Steffes S, Strittmatter A (2016) Return-to-job during and after parental leave. Int J Hum Resour Manag 27:803-831

Fortin NM, Lemieux T, Firpo S, Ashenfelter O, Card D (2011) Decomposition methods in economics. In: Handbook of Labor Economics, vol 4, North Holland, Amsterdam. pp 1-102

Gartner J (2005) The Imputation of wages above the contribution limit with the German IAB employment sample. In: FDZ Methodenreport No. 2, Institut für Arbeitsmarkt und Berufsforschung (IAB), Nürnberg

Gernandt J, Pfeiffer F (2007) Rising wage inequality in Germany. J Econ Stat 227:359-380

Gregory M, Jukes R (2001) Unemployment and subsequent earnings: estimating scarring among British men, 1984-94. Econ J 111:F607-F625

Heckman JJ (1981) Structural Analysis of Discrete Data, chapter 3. In: Manski C, McFadden D (eds). MIT Press, Cambridge, MA

Kohn K (2006) Rising wage dispersion, after all! The German wage structure at the turn of the century. IZA Institute of Labor Economics, Bonn

Lemieux T (2006) Increasing residual wage inequality: composition effects, noisy data, or rising demand for skill? Am Econ Rev 96:461-498

Manning A, Petrongolo B (2008) The part-time penalty for women in Britain. Econ J 118:28-51

Möller J (2016) Lohnungleichheit - Gibt es eine Trendwende? Wirtschaftsdienst 96(1):38-44

Paul M (2016) Is there a causal effect of working part-time on current and future wages?. Scand J Econ 118:494-523

Potrafke N (2012) Unemployment, human capital depreciation and pension benefits: an empirical evaluation of German data. J Pension Econ Finance 11:223-241

Riphahn RT, Schnitzlein D (2016) Wage mobility in East and West Germany. Labour Econ 39:11-34

Ruhm C (1991) Are workers permanently scarred by job displacements? Am Econ Rev 81:319-324

OECD (2010) OECD Employment Outlook 2010: Moving beyond the Jobs Crisis. OECD Publishing, Paris. https://doi.org/ 10.1787/empl_outlook-2010-en

Sachverständigenrat zur Begutachtung der Gesamtwirtschaftlichen Entwicklung [SVR] (2014) Mehr Vertrauen in Marktprozesse, Jahresgutachten 2014/15. Metzler-Poeschel, Stuttgart

Schmieder JF, von Wachter T, Bender S (2010) The long-term impact of job displacement in Germany during the 1982 recession on earnings, income, and employment IAB Discussion Paper No. 1/2010. Institut für Arbeitsmarkt und Berufsforschung (IAB), Nürnberg

Tamm M, Bachmann R, Felder R (2017) Erwerbstätigkeit und atypische Beschäftigung im Lebenszyklus - Ein Kohortenvergleich für Deutschland. Perspekt Wirtschpolit 18:263-285

Tisch A, Tophoven S (2012) Employment biographies of the German baby boomer generation. J Appl Soc Sci Stud (Schmollers Jahrbuch) 132:205-232 